\title{
A Study on Ordinary Portland Cement Blended with Rice Husk Ash and Metakaolin
}

\author{
Olumide Olu Olubajo ${ }^{1}$, Isa Yusuf Makarfi ${ }^{2}$, Menta Samuel Ibrahim ${ }^{1}$, Sholaremi Ayeni ${ }^{1}$, \\ Nwuchu William Uche ${ }^{1}$
}

${ }^{1}$ Abubakar Tafawa Balewa University

Dass road, P. M. B. 0248, Bauchi, 740272, Nigeria

${ }^{2}$ Durban University of Technology

P. 0. Box 1334, Durban, 4000, South Africa

DOI: $10.22178 /$ pos.54-4

LCC Subject Category: QD1-65

Received 20.12.2019

Accepted 27.01.2020

Published online 31.01.2020

Corresponding Author:

Olumide Olu Olubajo

ooolubajo@atbu.edu.ng

(C) 2020 The Authors. This article

is licensed under a Creative

Commons Attribution 4.0 License (c) (1)
Abstract. This paper tries to investigate the effect of replacing Ordinary Portland cement (OPC) with Metakaolin (MK) and Rice husk ash (RHA) on the physicomechanical properties such as consistency, setting times, soundness and mortar compressive strength of ternary cement up to $40 \%$ cement replacement. The soundness of the blended cement pastes and compressive strength of the blended mortars were conducted using Le Chatelier apparatus and Tonic Technic compression machine while the initial and final setting times were conducted on the blended cement paste using Vicat apparatus.. Nineteen ternary cement mortars were prepared to comprise of OPC, RHA MK at different proportions and tested at 2, 7, 28 and 60 days. Results indicated that as RHA was gradually increased up to $25 \%$ at constant MK content, the volume expansion of the ternary cement paste increased gradually. On the other hand, as MK was increased from $5-25 \%$ at constant RHA, the volume expansion diminished. The water consistency of ternary cement paste experienced a variation as MK was increased up to $25 \mathrm{wt} \%$ at constant RHA up to $10 \mathrm{wt} \%$. However, at $10 \mathrm{wt} \%$ constant RHA as MK was increased the water demand gradually increased. Similarly, an increase in RHA at constant MK increased the water demands of the ternary blends. An increase in RHA from 5$25 \mathrm{wt} \%$ at $5-25 \mathrm{wt} \%$ constant MK resulted in acceleration in the initial and final setting times of cement blends. These accelerations could be attributed to the pozzolanic activity leading in shorter setting time. Whereas a series of accelerations and retardations of both setting times were experienced as the MK was increased from $5-25 \mathrm{wt} \%$ at $5-25 \mathrm{wt} \%$ constant RHA. It was observed that increment in the MK or RHA up to $10 \mathrm{wt} \%$ at constant RHA/MK up to 10 $\mathrm{wt} \%$ resulted in improved mortar compressive strength of the ternary blend in comparison with control. This improvement was attributed to the high silica/alumina contribution to the matrix by MK inclusion, the $\mathrm{C} / \mathrm{S}$ ratio in the cement matrix and RHA pozzolanic reactivity despite its unburnt carbon. All mortar compressive strength of the cement blends and control experienced an increase as the curing days were lengthened from 2 to 60 days. The enhanced strength compared with the control especially beyond 28 days could be attributed to the slow pozzolanic reaction resulting from the formation of additional $\mathrm{CSH}$ and $\mathrm{CAH}$ from the interaction of the residual $\mathrm{CH}$ and the silica available in the MK and RHA. The best compressive strength at 60 days was obtained at cement replaced with $15 \mathrm{wt} \%$ and $20 \mathrm{wt} \%$ at MK $5 \mathrm{wt} \% \mathrm{RHA}$ producing a mortar compressive strength of $40.5 \mathrm{MPa}$.

Keywords: Metakaolin; Rice husk ash; Consistency; Setting time; Soundness and Compressive Strength. 


\section{INTRODUCTION}

In recent times, there has been an excessive excavation of specific natural resources for cement production, thus resulting in scarcity of these resources; on the other hand, the cement production process is very energy-intensive. This negative trend has caused researchers to sort for other alternatives. One of the alternatives involve the use of pozzolanic materials such as metakaolin (MK), rice husk ash (RHA), fly ash (FA) and silica fume(SF). These cementitious materials have been used in recent decades for improving the performance of concrete with improved workability, strength, and durability [1]. Pozzolanic reactions change the microstructure of concrete and chemistry of the hydration products by consuming the released calcium hydroxide $(\mathrm{CH})$ and producing additional calcium silicate hydrates (C-S-H), resulting in increased strength and reduced porosity and therefore improved durability [2]. Rice is the daily staple for more than 3.5 billion people, however, with high demand for rice, its growth is expected to increase [3]. This growth experienced in the agricultural sector has also led to the increase in agricultural waste such as rice husk which can constitute an environment challenge, hence the necessity to convert into value-added materials, thus minimizing environmental problems [4]. RHA is obtained from the combustion of rice hull at controlled temperature; from works of various researchers. RHA has been found to provide several properties ranging from improved workability at low replacement levels and low heat of hydration, lower creep, and shrinkage. Studies by $[5,6,7,8]$ have shown outstanding technical benefits of incorporating RHA in which it significantly improves the durability properties of concrete. Authors [9] also reported that the RHA inclusion up to $15 \mathrm{wt} \%$ led to compressive strength increments and above these values led to a decrease in compressive strength. Author [10] reported increased compressive and flexural strengths as a result of cement replacement with RHA. Researcher [11] reported that the RHA replacement level in excess than $30 \mathrm{wt} \%$ could lead to a reduction in strength. Authors [12] reported that the cement replacement level was investigated between $10-20 \mathrm{wt} \%$ and was discovered to attain an optimal level of $15 \mathrm{wt} \%$ RHA replacement.

Metakaolin is a unique pozzolanic material obtained from the calcination of clay materials kaolinitic clay [13]. Due to its high reactivity with calcium hydroxide and its ability to haste cement hydration [14, 15], the use of MK as an SCM has been intensively investigated. Authors [16] gave the result of an increment in the compressive strength for 28 days up to $10 \mathrm{wt} \%$ while [17] reported that after 28 curing days, the concrete compressive strength at various MK replacement levels from 5-30 wt\% experienced an increment up to $32 \mathrm{wt} \%$, with an optimum MK level at $20 \mathrm{wt} \%$. Authors [18] reported that cement replacement of 5-10 wt $\%$ MK exhibited enhanced strengths at ages up to 365 days. The factors identified contributing to the concrete strength by the inclusion of MK include filler effect, acceleration of Portland cement hydration and pozzolanic reactions [17]. Researchers [19] reported that at $15 \mathrm{wt} \%$ RHA replacement and $25 \mathrm{wt} \%$ MK replacement, the compressive strength was enhanced by $20.9 \%$ and $17.42 \%$ respectively whereas cement blended with 15 wt $\%$ RHA and 15 wt $\%$ MK enhanced the strength by $24.61 \%$.

This paper tries to understand and examine the effect of RHA and MK on the physical property of blended cement paste such as water consistency, setting time and soundness as well as the mortar compressive strength of various cement blends and control.

\section{REVIEW OF LITERATURES}

According to [20], the effect of cement replacement with RHA at $10-30 \mathrm{wt} \%$ at an interval of $10 \%$ on concrete properties, observed that the initial and final setting times increased as the RHA content was increased. Similarly, [21] observed that the high silica content of RHA chemical composition contributes to the concrete workability. Other researchers also indicated that owing to the high amorphous silica content present in RHA, it can be considered as an SCM to be employed as a cement replacement [22, 23, $24,25]$. The inclusion of RHA into the cement matrix resulted in an increase in the setting time which could be attributed to the diminution of the clinker content which contributes to the slow exothermic reaction between the diminished cement and water leading to slowness in stiffness of the paste and evaporation of water [21, 26, 27, 28]. Similarly, the trend of increase in both setting time of cement blended with RHA was observed by $[11,29]$.

Authors [30] observed that no significant difference in the mortar compressive strength of ce- 
ment blended with $10 \mathrm{wt} \%$ RHA of $45 \mu \mathrm{m}$ sieve size in comparison with control while [31] observed that cement replacement with $25 \mathrm{wt} \%$ RHA produced similar concrete compressive and tensile strength while the flexural strength showed slight improvements. Authors [32] also observed that cement blended with $10 \mathrm{wt} \%$ RHA, produced better strengths at 28 days i.e. compressive, flexural and tensile compared to the control and their workability diminished as the RHA content was gradually increased from 0$25 \mathrm{wt} \%$ due to decrease in the compaction factor by $43.02 \%$. Authors [33] observed similar trends of decrease in workability as the RHA content was increased. He also investigated the effect of RHA density on the workability and compressive strength of fresh and hardened RHA concrete respectively and concluded that an increase in the RHA content by weight (RHA-W) led to a decrease in its concrete density while an increase in RHA content by volume (RHA-V) led to an increase in its density as the curing days progressed up till $20 \%$ beyond which experienced a decrease in density respectively. This decrease in the density of RHA-W was attributed to the consumption of $\mathrm{Ca}(\mathrm{OH})_{2}$ during pozzolanic reaction which occurs due to secondary hydration to form CSH which is less dense [34, 35, 36], whereas a decrease in workability was observed as the cement replacement was increased for both RHA$W$ and RHA-V. Authors [37] investigated the effect of RHA on the physicomechanical properties of the aggregate cement bricks and results indicated that the compressive strength increased as curing time progressed and its strength decreased as RHA content was increased. Similarly, the water consistency of the RHA cement blend increased as cement was replaced with $10 \mathrm{wt} \%$ RHA. Researchers [38] investigated the effect of partial replacement of cement with RHA on the workability and compressive strength and observed that the strength was enhanced as the RHA content was increased from 10-20 wt $\%$ whereas, at $30 \mathrm{wt} \%$, the strength was similar to that of control. The workability of RHA cement blends decreases as the RHA content was increased. Authors [39] investigated the effect of replacing 20 wt $\%$ of cement with RHA on the compressive strength and observed that the compressive strength was enhanced by 2.98 , $2.76,3.01 \%$ at 14,21 and 28 days respectively, whereas at 7 days strength of the cement blend was lower compared to control. Researchers [38, 39] suggested that RHA reactivity was influenced by the silica content, silica crystalline phase and the size and surface area of the ash particle. Author [40] also investigated the effect of RHA on the concrete strength and observed that the 28 days compressive strength increased by $30 \%$ as the RHA was increased from $0-15 \%$ beyond which the compressive strength diminished by $11.57 \%$ of the control strength.

According to [41], the water demand increased by 103 and $112 \%$ as the RHA content was increased to 10 and $30 \%$ respectively and this increment was attributed to the RHA fineness and porous surface area. This increment in the water demand agreed with $[42,43]$. He also observed that the initial setting time retarded as the RHA content increase while the final setting time accelerated as the RHA content was increased. Similarly, $15 \%$ cement replacement with RHA produced $93.4 \%$ of the strength at 28 days which agreed with $[23,58]$ with optimal replacement at $15 \%$. Authors [16, 44] optimal at $10 \%$ and researchers [45] suggested that the optimal cement replacement for compressive, flexural and tensile strengths was at $5 \%$. RHA inclusion decrease $\mathrm{Ca}(\mathrm{OH})_{2}$ content resulting in excess silica present in RHA which reacts to produce $\mathrm{CSH}$ gel which strengthening constituents $[46,47]$. Author [25] observed that the RHA cement mortars produce higher strength than the control mix at lower cement replacement but at high cement, replacement experienced a reduction.

\section{MATERIALS AND METHODS}

Ternary blends were prepared from replacing Ordinary Portland cement with RHA and MK. The cement replacement was less than or equal to $40 \%$ by weight of the ordinary Portland cement were employed. Nineteen different ternary cement blends were prepared using ordinary Portland cement, RHA and MK in various proportions as summarized in Table 1. A Nigerian commercial ordinary portland cement (OPC) type $32.5 \mathrm{R}$ according to Nigeria Industrial Standard (NIS) was supplied by Ibeto cement company and used as a control. The rice husks were collected in Yelwa, Bauchi metropolis, Bauchi State. RHA was obtained from the combustion of rice husk in a ceramic furnace at a temperature range of $600{ }^{\circ} \mathrm{C}$ for 3 hours. The resulting ash was then ground in a ball mill to a particle size less than $65 \mu \mathrm{m}$. Raw kaolin was obtained from Alkaleri village which was beneficiated and calcined at a temperature 
of $700{ }^{\circ} \mathrm{C}$ for 2 hours, after which cooled to get MK as reported in our previous work [48]. The chemical and mineralogical composition was determined with an X-ray Fluorescence machine (XRF) and X-ray Diffractometer (XRD). The physical characteristics and chemical composi- tion of OPC, RHA, and MK were tabulated in Table 2 while the X-ray Diffractometer (XRD) of RHA and MK were illustrated in Figures 1 and 2. The Blaine surface of RHA and MK were determined as $298 \mathrm{~m}^{2} / \mathrm{kg}$ and $323 \mathrm{~m}^{2} / \mathrm{kg}$ via Blaine surface area equipment respectively.

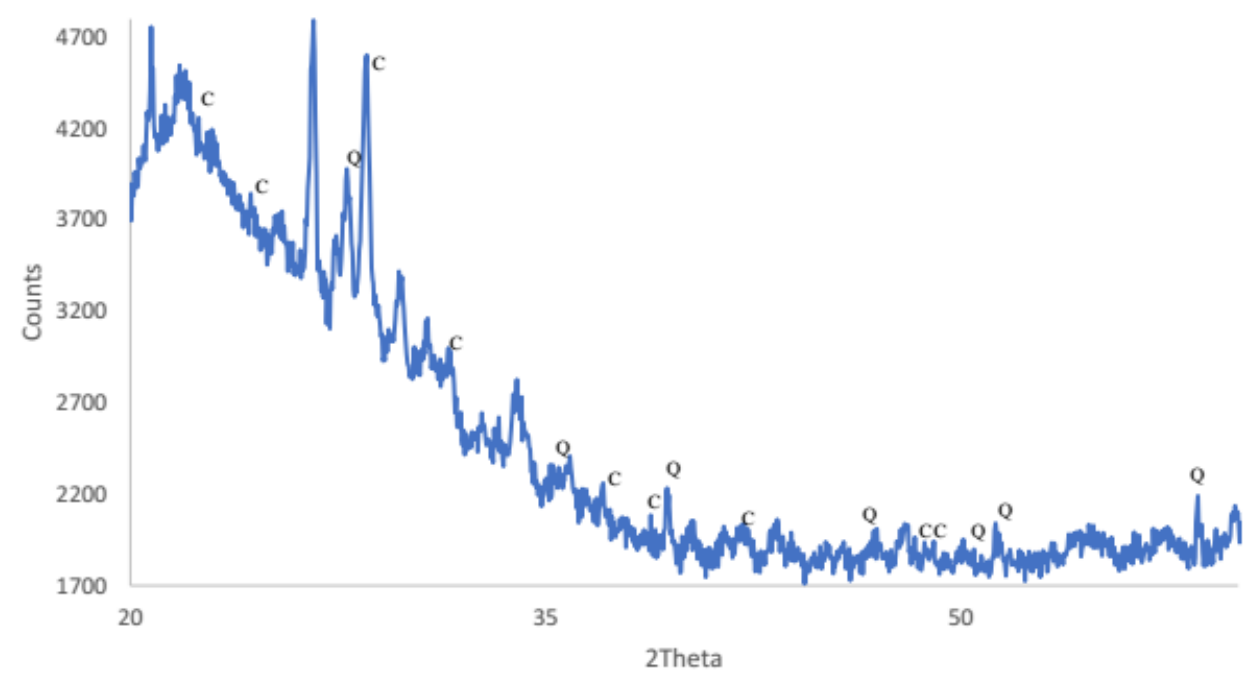

Figure 1 - X-ray Diffraction for RHA

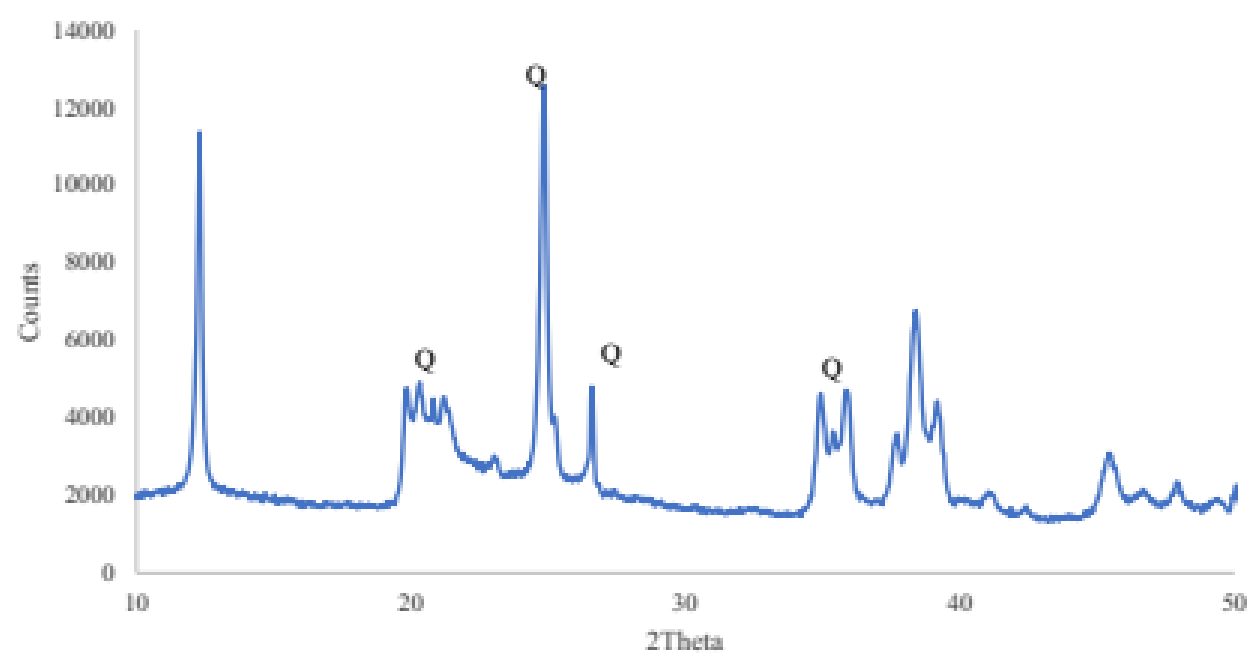

Figure 2 - X-ray diffraction for MK

The required water of standard consistency, initial and final setting time were determined according to [49] through the use of a Vicat apparatus while the soundness was determined with Le Chatelier apparatus according to [50]. The mixing of blended cement pastes was carried out with the standard water of consistency as given in Table 2. The compressive strength test was carried out on mortar samples mixed using water: binder: sand at a ratio of 1:2:5. The mix was then cast in the oiled mold of $50 \mathrm{~mm}$ cubes after which were compacted after vibrating with a jolt- ing machine for 2 minutes. The molds were then surface smoothed and covered with an impervious sheet to avoid evaporation, after which were allowed to cure at room temperature for 24 hours. The cubes were demoulded after 24 hours and then placed in a curing tank containing distilled water for testing at the required ages of 2 , 7, 28 and 60 days. The samples were removed from the curing tank and tested for mortar compressive strength using the Tonic Technic compression machine. 
Table 1 - Chemical Composition of Ordinary Portland cement, RHA and MK

\begin{tabular}{|c|c|c|c|}
\hline Compound & OPC, \% & RHA, \% & $\mathrm{MK}, \%$ \\
\hline $\mathrm{SiO}_{2}$ & 20.25 & 81.28 & 53.15 \\
\hline $\mathrm{Al}_{2} \mathrm{O}_{3}$ & 5.08 & 2.42 & 40.20 \\
\hline $\mathrm{Fe}_{2} \mathrm{O}_{3}$ & 3.48 & 0.71 & 1.54 \\
\hline $\mathrm{CaO}$ & 62.35 & 0.75 & 0.57 \\
\hline $\mathrm{MgO}$ & 3.80 & 1.09 & 0.14 \\
\hline $\mathrm{SO}_{3}$ & 2.61 & 0.23 & 0.01 \\
\hline $\mathrm{K}_{2} \mathrm{O}$ & 0.81 & 4.02 & 0.22 \\
\hline $\mathrm{Na}_{2} \mathrm{O}$ & 0.17 & 0.18 & 0.05 \\
\hline $\mathrm{TiO}_{2}$ & 0.28 & - & 2.79 \\
\hline $\mathrm{Mn}_{2} \mathrm{O}_{3}$ & 0.16 & 0.23 & \\
\hline $\mathrm{P}_{2} \mathrm{O}_{5}$ & 0.12 & 5.73 & \\
\hline $\mathrm{Cl}$ & 0.05 & - & 0.00 \\
\hline Cr203 & 0.84 & - & \\
\hline Sum of Conc. & 100.00 & 100.00 & 100.00 \\
\hline LSF & 96.02 & - & - \\
\hline $\mathrm{C}_{3} \mathrm{~S}$ & 52.30 & - & - \\
\hline $\mathrm{C}_{2} \mathrm{~S}$ & 17.56 & - & - \\
\hline $\mathrm{C}_{3} \mathrm{~A}$ & 7.51 & - & - \\
\hline $\mathrm{C}_{4} \mathrm{AF}$ & 10.49 & - & \\
\hline LOI & & 3.36 & 1.25 \\
\hline Specific gravity & 3.15 & 2.36 & 2.60 \\
\hline $\begin{array}{r}\text { Blaine fineness, } \\
\mathrm{m}^{2} / \mathrm{kg}\end{array}$ & - & 298 & 323 \\
\hline
\end{tabular}

Table 2 - Mix Proportion and water of consistency and initial and final setting time of blends

\begin{tabular}{|l|r|r|r|r|}
\hline No & $\begin{array}{c}\text { OPC- } \\
\text { RHA-MK }\end{array}$ & $\begin{array}{c}\text { Water } \\
\text { cement } \\
\text { ratio, } \mathrm{w} / \mathrm{c}\end{array}$ & $\begin{array}{c}\text { Initial } \\
\text { setting } \\
\text { time, min }\end{array}$ & $\begin{array}{c}\text { Final setting } \\
\text { time, min }\end{array}$ \\
\hline 1 & $100-0-0$ & 0.300 & 50 & 335 \\
\hline 2 & $90-5-5$ & 0.323 & 65 & 325 \\
\hline 3 & $85-5-10$ & 0.333 & 65 & 275 \\
\hline 4 & $85-10-5$ & 0.380 & 45 & 225 \\
\hline 5 & $80-5-15$ & 0.350 & 55 & 245 \\
\hline 6 & $80-15-5$ & 0.433 & 45 & 195 \\
\hline 7 & $80-10-10$ & 0.383 & 55 & 220 \\
\hline 8 & $75-5-20$ & 0.350 & 60 & 205 \\
\hline 9 & $75-20-5$ & 0.493 & 45 & 145 \\
\hline 10 & $75-10-15$ & 0.383 & 50 & 225 \\
\hline 11 & $75-15-10$ & 0.417 & 50 & 205 \\
\hline 12 & $70-5-25$ & 0.350 & 55 & 220 \\
\hline 13 & $70-10-20$ & 0.390 & 55 & 160 \\
\hline 14 & $70-15-15$ & 0.427 & 50 & 150 \\
\hline 15 & $70-20-10$ & 0.457 & 40 & 125 \\
\hline 16 & $70-25-5$ & 0.523 & 35 & 110 \\
\hline 17 & $65-10-25$ & 0.393 & 40 & 140 \\
\hline 18 & $65-15-20$ & 0.433 & 45 & 105 \\
\hline 19 & $65-20-15$ & 0.467 & 35 & 95 \\
\hline 20 & $60-20-20$ & 0.497 & 45 & 110 \\
\hline
\end{tabular}

\section{RESULTS AND DISCUSSION}

The chemical composition of RHA indicated oxides like silica, alumina and ferric oxide which were greater than $70 \%$ (84.31\%). Thus, considered a good pozzolan since ASTM C618 for $\mathrm{SiO}_{2}+\mathrm{Al}_{2} \mathrm{O}_{3}+\mathrm{Fe}_{2} \mathrm{O}_{3}$ more than $70 \%$ was satisfied. The silica content of RHA employed in this study was $81.28 \%$ with literature ranging between 77-94\% [25]. The second and third main constituents of RHA are Phosphorus (V) oxide and Potassium of $5.73 \%$ and $4.02 \%$ which fell within the range of $3-7 \%$ and $4-10 \%$ respectively [51]. Other major constituents include $\mathrm{Al}_{2} \mathrm{O}_{3}(2.42 \%)$, $\mathrm{MgO}(1.09 \%)$ as well as the minor constituents such as $\mathrm{Fe}_{2} \mathrm{O}_{3}, \mathrm{CaO}, \mathrm{SO}_{3}, \mathrm{Na}_{2} \mathrm{O}$ and $\mathrm{Mn}_{2} \mathrm{O}_{3}$ (less than $1 \%$ ). The specific gravity/ density of RHA was found to be 2.31 which was higher than the range of $1.41-2.23$ [24, 25, 52, 53].

The high density could be attributed to the particle size of the RHA i.e. the higher the density the higher the particle size and vice visas [42]. The carbon content is determined as LOI was $3.36 \%$ which satisfies the ASTM requirement for LOI which should not exceed $12 \%$. MK contains major components like silica, alumina and while minor components like ferric oxide which were greater than $70 \%$ (95.92\%). Thus, considered a good pozzolan since ASTM C618 for $\mathrm{SiO}_{2}+\mathrm{Al}_{2} \mathrm{O}_{3}+\mathrm{Fe}_{2} \mathrm{O}_{3}$ more than $70 \%$ was satisfied. The specific gravity of MK was found to be 2.60 which agreed with ranges from the literature [54]. The LOI of MK was $1.25 \%$ which satisfies the ASTM requirement for LOI which should not exceed $12 \%$.

Figure 1 depicts the diffractogram for RHA indicated by silica peaks at value observed at respectively and comprised of about $95.4 \%$ silica with other minor constituents while the mineralogical composition of $\mathrm{MK}$ is indicated from the XRD pattern illustrated in Figure 2. The diffraction spectra indicated the presence of quartz and amorphous aluminum silicate phases which agree with [54].

Figure 1 illustrates XRD patterns for RHA calcined at $600{ }^{\circ} \mathrm{C}$ for 2 hours. The results indicated that Cristobalite is the main crystal phase of RHA at 2 Theta of 22, 25.3, 28.5, 31.5, 36, 36.25, 38.5, $43.1,45,47$, and $48.5{ }^{\circ} \mathrm{C}$ while Quartz was detected at 2 Theta of $21,27.5,36.5,39.5,45,50.3$, $50.8,55,55.2$, and $60{ }^{\circ} \mathrm{C}$ respectively. The amorphous silica present in RHA is essential in determining the pozzolanic reactivity when combined 
with lime and water and this degree can be estimated via XRD.

From the mineralogical composition of MK, the diffraction spectra indicated the presence of quartz and amorphous aluminum silicate phases. The results indicated that Quartz is one of the main crystal phase of MK at 2 Theta of 20.8, 24.8, 26.6, 34.9. The reactivity of MK is dependent on the Penta coordinated Aluminum ions formed during the dehydroxylation process according to [55].

\section{Water requirement for consistency of the ternary blends}

Effect of MK content on the water requirement for consistency at constant RHA content. Figure 3 illustrates the effect of $\mathrm{MK}$ at constant RHA content on the consistency of the ternary cement blend. A gradual increase in the consistency was observed as the MK content was increased from 5-25 wt\% cement replacement at constant RHA of $5 \mathrm{wt} \%$ and $10 \mathrm{wt} \%$ respectively.

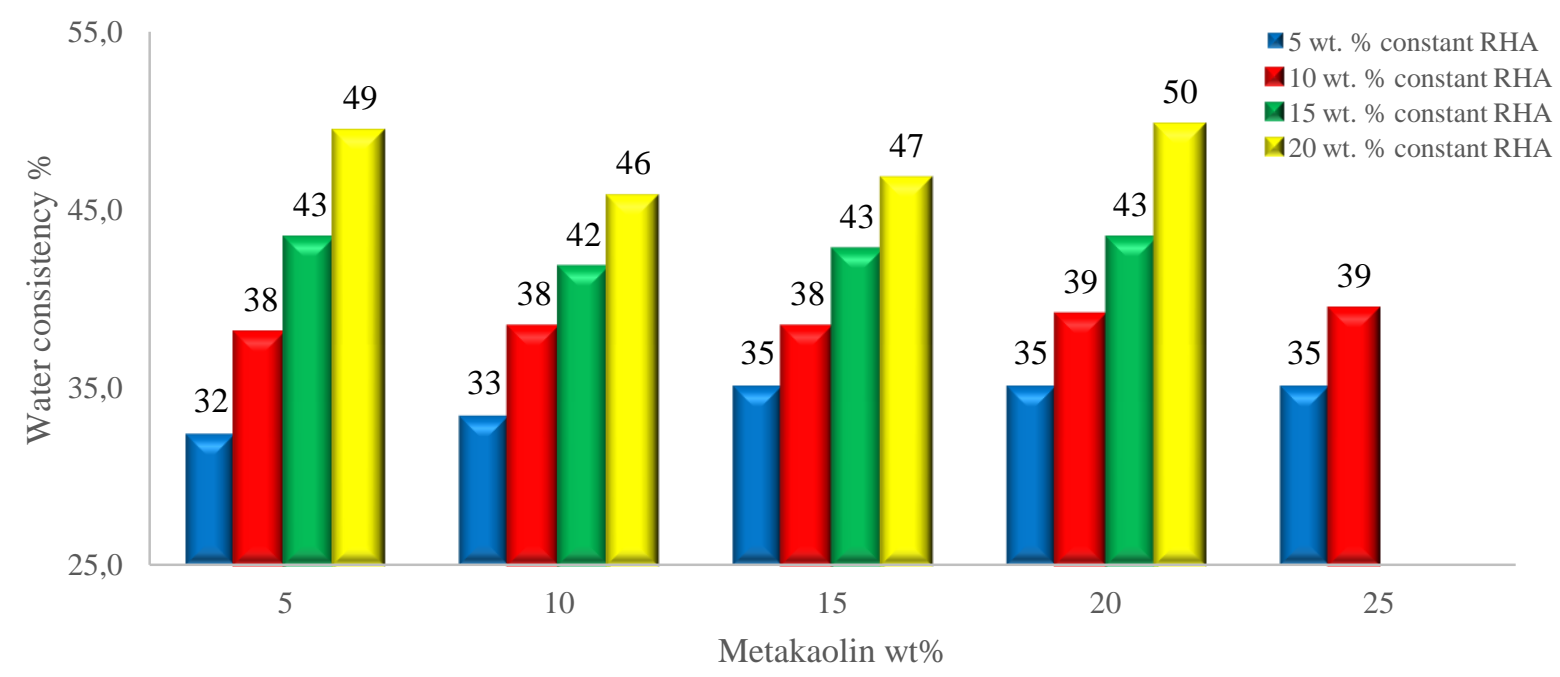

Figure 3 - Effect of MK at constant RHA on the consistency of ternary blend

The reason for the increased consistency as the MK content increased could be attributed to the high reactivity of the MK stemming from the high specific surface area and amorphous structure $[54,56]$ coupled with the presence of RHA which contains unburnt carbon resulting in more water requirement. This trend is also in agreement with [54, 56, 57]. Whereas, at 15 and 20 wt\% constant RHA content, an increase in the MK content led to an initial decrease followed by an increase in the consistency of the ternary cement blend. The initial decrease in the consistency could be attributed to the diminution of the clinker content but experienced an increase in the water consistency as the MK content was increased due to its reactivity.

Effect of RHA content on the water requirement for consistency at constant MK content. Figure 4 illustrates the effect of RHA at constant MK on the consistency of the ternary cement blend. The water requirement for normal consistency at constant MK from 5-20 wt\% indicates an in- crease as the RHA content increased. This increment in water requirement can be attributed to the high surface area due to the amorphous nature and the unburnt carbon particle present in the RHA [27, 28], a similar trend was observed according to [5]. A similar trend of an increase in the RHA content at constant MK content resulted in a decrease in the workability of the cement paste blended with RHA which was in agreement with works by $[37,59,60]$. It could be observed that RHA significantly contributed to the water demand of the cement blend compared to the MK. The water required for normal consistency ranged from $0.323-0.523$ for RHA increment at constant MK content from 5-20 wt\%. According to [41], the water demand increased by $103 \%$ and $112 \%$ when RHA was increased from 10$30 \%$ whereas resulted from increasing RHA at constant MK from 5-25 wt\% led to increasing in the water demand by 107.7 to $174.3 \%$. 


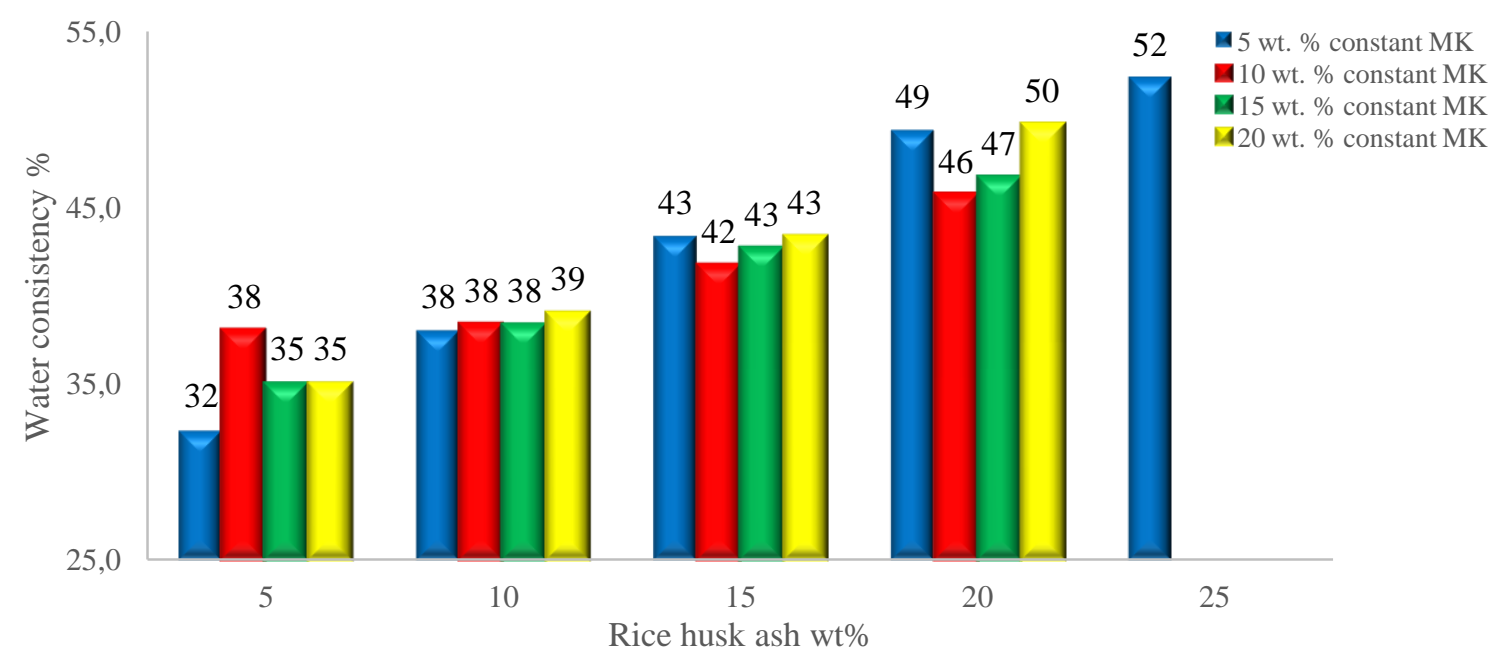

Figure 4 - Effect of RHA at constant MK on consistency of ternary blend

\section{Setting time of ternary cement blends}

Effect of RHA content at constant MK content on the setting time. Figures 5 and 6 indicate the effect of RHA at constant MK content on the initial and final setting time of ternary cement blends respectively. Contrary to $[20,37,59,60]$, an elongation of the initial and final setting time of RHA cement blend as the RHA content increases, It was observed that as the RHA content was gradually increased at constant MK content there was an acceleration in the initial setting time (shorter time). An increase in the RHA content from $5-25 \mathrm{wt} \%$ at $5 \mathrm{wt} \%$ constant MK content resulted in acceleration from 65 to 35 minutes for initial setting time. Similar trends were observed for 10, 15 and 20 wt\% constant MK con- tent as the RHA was gradually increased. This acceleration in the setting times could be attributed to the presence of MK as well as the high RHA reactivity due to the high siliceous content which reacts with $\mathrm{Ca}(\mathrm{OH})_{2}$ during hydration to form calcium silicate hydrate, thus, resulting in shorter setting time. Other researchers also indicated that owing to RHA high amorphous silica content and its fineness could be contributory factor to the reduction of setting time as a result of rapid solubility of the siliceous content in the RHA, thus, leading to quicker pozzolanic reaction since RHA reactivity is influenced by the silica content, silica crystalline phase, and the size and surface area of the ash particle [38, 39].

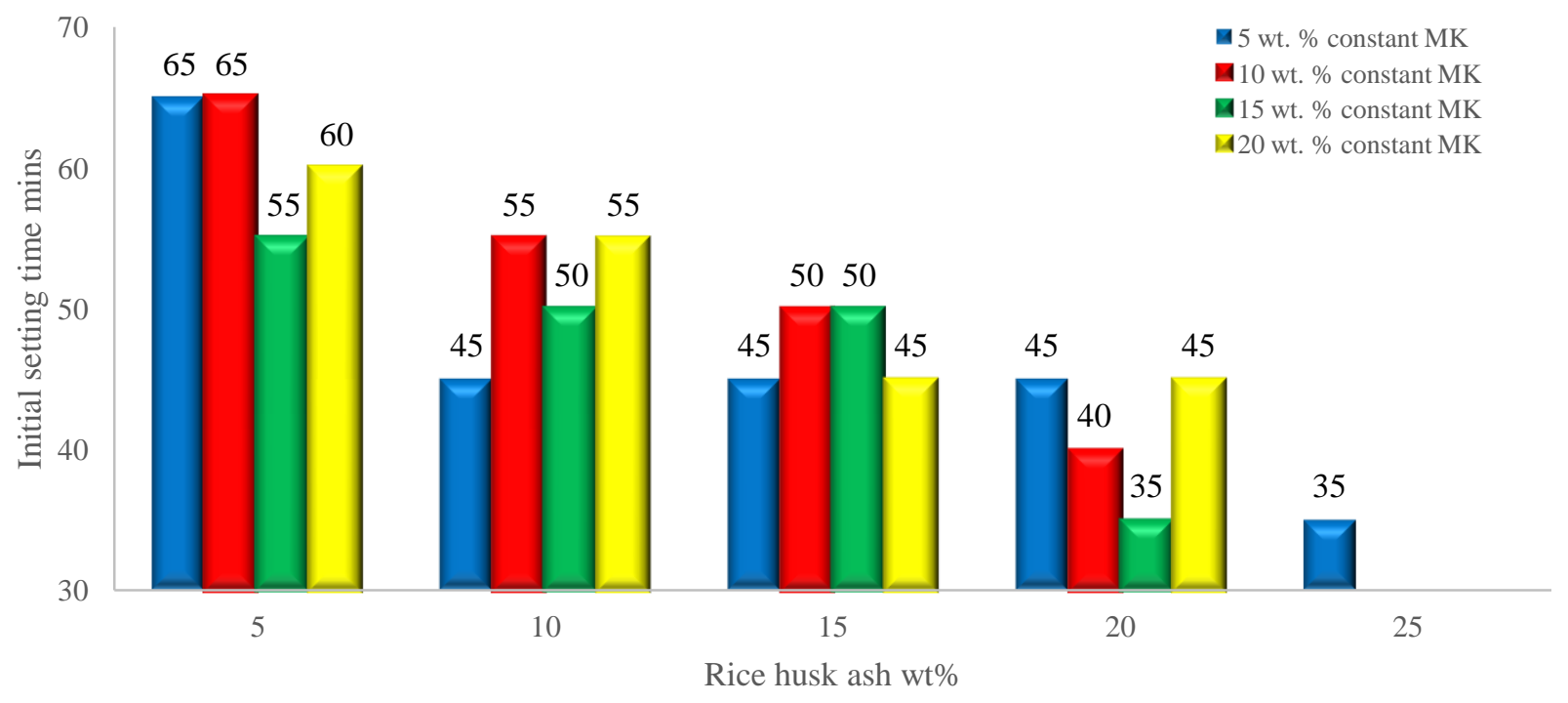

Figure 5 - Effect of RHA content at constant MK content on initial setting time of ternary blends 


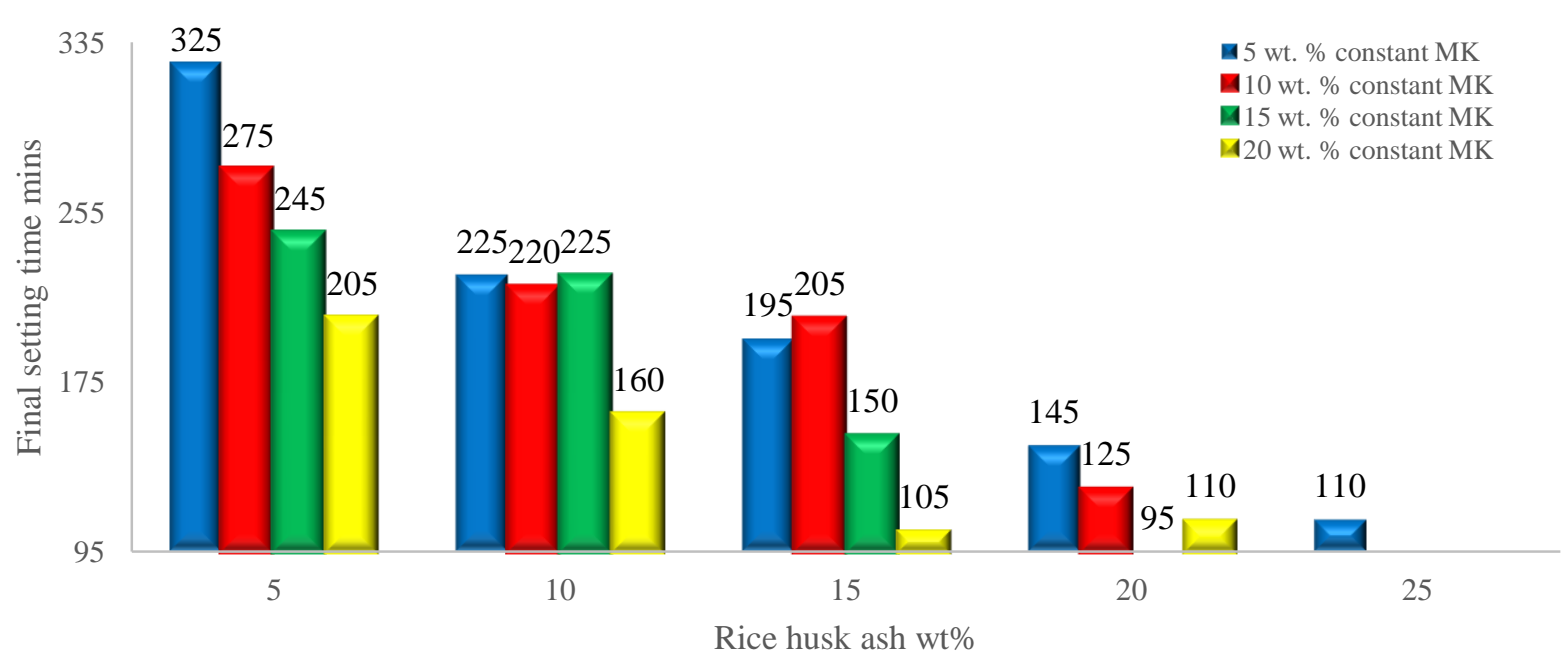

Figure 6 - Effect of RHA content at constant MK content on final setting time of ternary blends

Similarly, the final setting time diminished (accelerated setting time) was observed as RHA was gradually increasing at constant MK content. This can be attributed to the solubility of the RHA which was enhanced by improved surface area at the expenses of the gypsum and enter into reaction with calcium hydroxide during hydration, thus, the function of gypsum to regulate the setting time is interrupted resulting in acceleration of the final setting time.

Effect of MK content at constant RHA content on the setting time. Figures 7 and 8 illustrate the effect of MK content at various constant RHA content on the initial and final setting time at standard consistency of ternary cement respectively. As the MK content was increased from $5-10$ wt $\%$ at $5 \%$ constant RHA, the initial setting time of the ternary cement blend experienced no significant change, whereas, any further increment in the MK content beyond $10 \mathrm{wt} \%$ resulted from a se- ries of acceleration and elongation in the initial setting time.

In general, a series of increases and decreases in the setting times as the MK content increases at constant RHA content was in agreement by [54] for binary blends. According to [54, 61] indicated no consistent change in the setting time produced as MK content increased up to $25 \mathrm{wt} \%$ at constant RHA content which was similar to results obtained as MK content was increased at constant RHA content.

A prolonged initial and final setting times could be attributed to the coating effect of MK particles on the cement matrix coupled with the ettringite formation as well as dilution of OPC as the MK content was increased. Whereas, the acceleration of the setting times could be due to a slight decrease in water consistency as the MK content was increased. Thus, it was observed that the cement replacement was independent of the MK content.

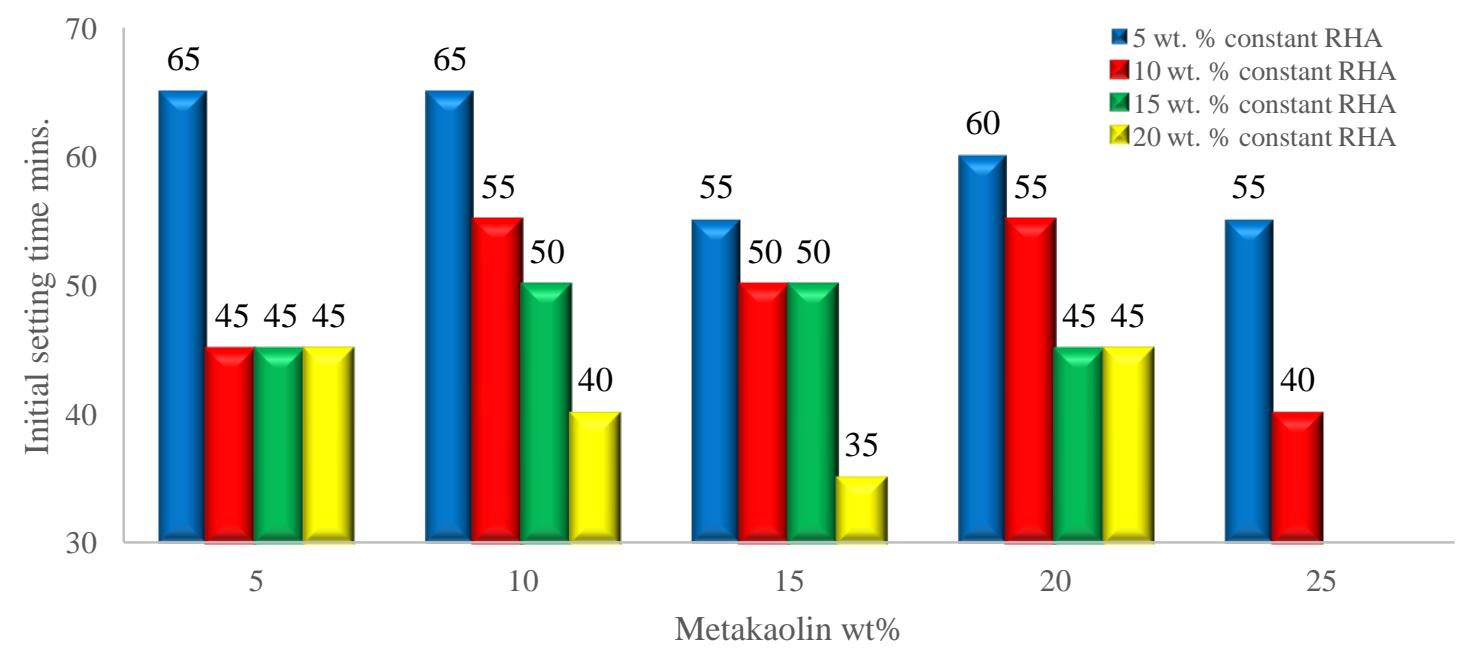

Figure 7 - Effect of MK content at constant RHA content on initial setting time of ternary blends 


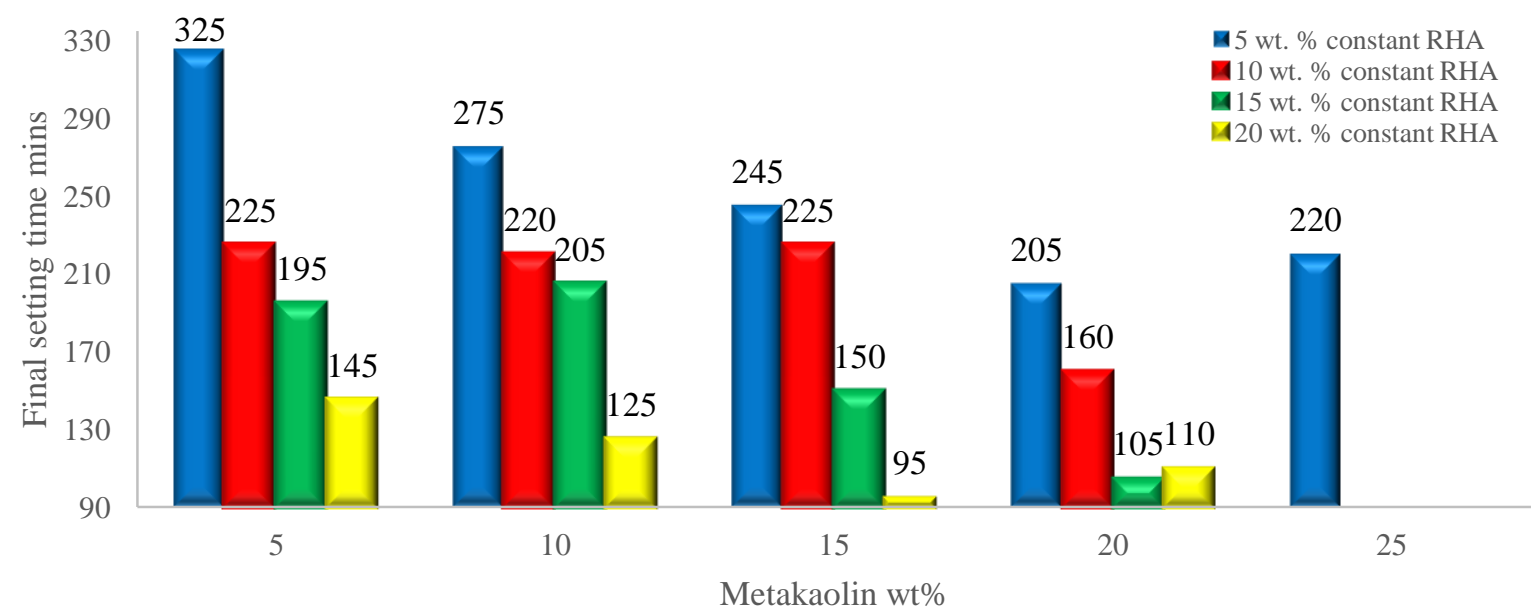

Figure 8 - Effect of MK content at constant RHA content on final setting time of ternary blends

\section{Volume expansion/soundness of the ternary blends}

Effect of RHA content on the soundness of Ternary Cement pastes at constant MK content. Figure 9 illustrates the effect of RHA content on the volume expansion (reduction in volume stability) of ternary cement paste at 5-20 wt\% constant $\mathrm{MK}$ content. An increase in the RHA content at $5 \mathrm{wt} \%$ constant MK content resulted in an increase in the volume expansion from $1.0 \mathrm{~mm}$ to $2.5 \mathrm{~mm}$. A similar trend of an increase in the volume expansion (reduction of volume stability) was experienced as the RHA content increased at constant MK content of 10,15 and $20 \mathrm{wt} \%$ respectively. This volume instability can be attributed to the presence of $\mathrm{CaO}$ and $\mathrm{MgO}$ evident in the RHA.

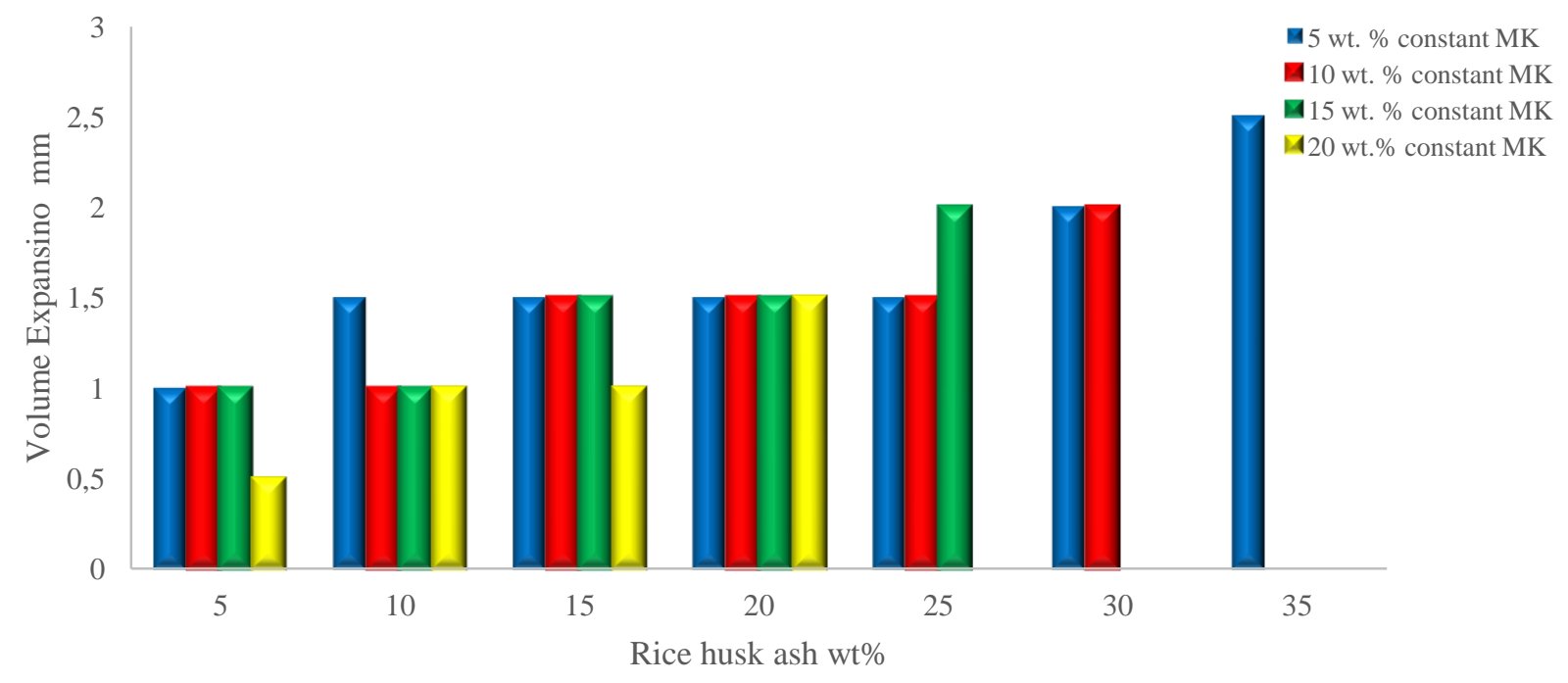

Figure 9 - Effect of RHA content at constant MK content on volume expansion of ternary blends

No significant change in the volume expansion was observed for the ternary cement blends between $10-25 \mathrm{wt} \%$ at $5 \mathrm{wt} \%$ constant MK content. This could be attributed to the pozzolanic reaction resulting in a reduction of the free lime. A similar trend was observed for between 5$10 \mathrm{wt} \%$ and $15-25 \mathrm{wt} \%$ RHA at $10 \mathrm{wt} \%$ constant MK content respectively. Ternary cement blends between $5-10 \mathrm{wt} \%$ and $15-20 \mathrm{wt} \%$ at $15 \mathrm{wt} \%$ constant MK also experienced no significant changes in the volume expansion possibly due to consumption of the available free lime that is responsible for unsoundness.

Effect of MK content on the soundness of ternary cement paste at constant RHA content. Figure 10 indicates a stepwise decrease of $0.5 \mathrm{~mm}$ in the volume expansion from 1.0 to $0.5 \mathrm{~mm}$ at $5 \mathrm{wt} \%$ constant RHA content whereas the volume expansion diminished from $1.5-0.5 \mathrm{~mm}$ as the MK content increases at 10 and $15 \mathrm{wt} \%$ constant RHA content respectively. This observed reduc- 
tion in the volume expansion may be attributed to the diminution of OPC which contains a significant $\mathrm{CaO} / \mathrm{MgO}$ constant responsible for unsoundness. Authors [62] indicated that the main factor responsible for the volume expansion is free $\mathrm{CaO}$ and $\mathrm{MgO}$ content in the cement matrix. They concluded that the expansion is due to delayed hydration of $\mathrm{CaO}$ and $\mathrm{MgO}$ to form $\mathrm{Mg}(\mathrm{OH})_{2}$ and $\mathrm{Ca}(\mathrm{OH})_{2}$.

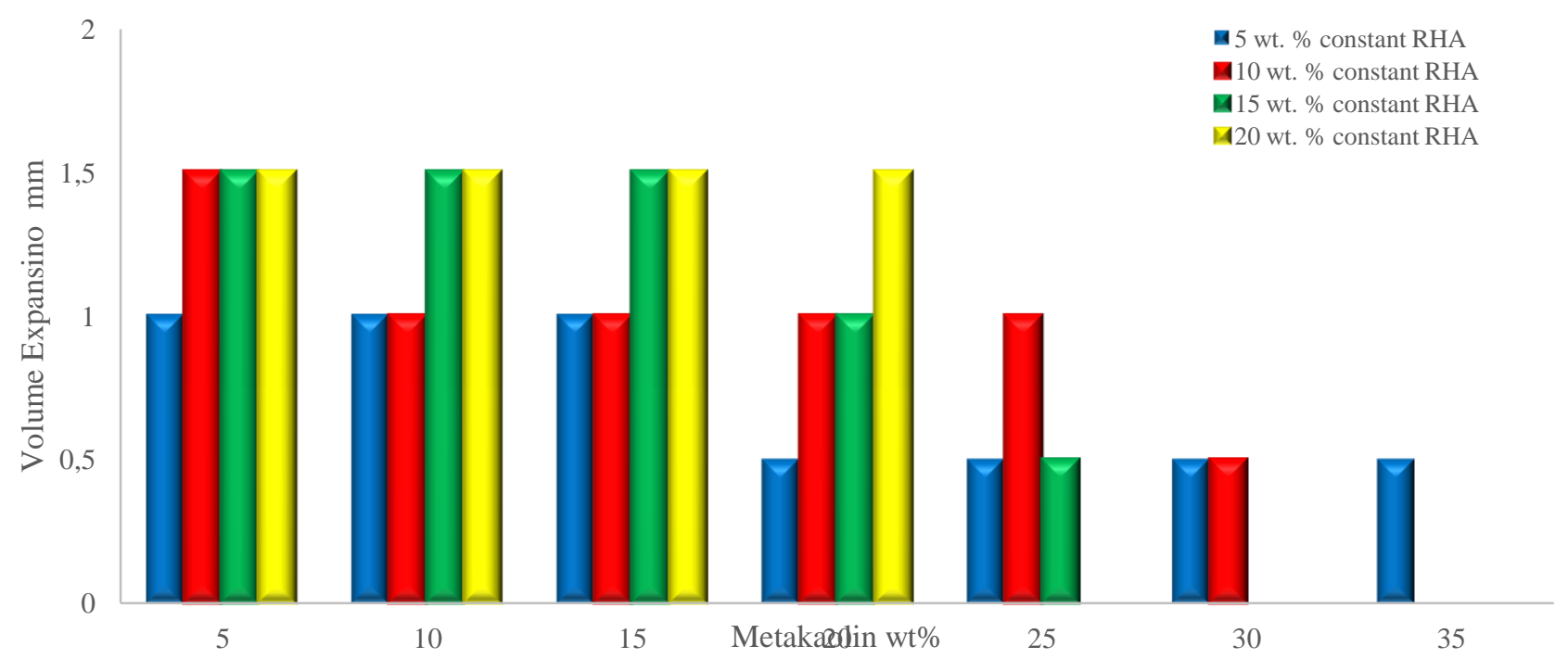

Figure 10 - Effect of MK content constant RHA content on volume expansion of ternary blends

It could be concluded that the RHA retarded the volume stability of the ternary blend, MK enhanced its stability owing to the presence of limited $\mathrm{CaO} / \mathrm{MgO}$ content in its matrix. The OPC had a volume expansion of $3.0 \mathrm{~mm}$ in comparison with those of ternary cement blend which were relatively lower. This confirms the fact that the $\mathrm{CaO}$ and $\mathrm{MgO}$ contents present in OPC were significantly high compared to that of RHA and MK respectively.

\section{Compressive strength of the ternary blends}

The effect of MK content on the mortar compressive strength of cement blend and control at 5$20 \mathrm{wt} \%$ constant RHA and the effect of RHA content on the mortar compressive strength of cement blends at constant 5-20 wt \% MK content are presented in Figures 11-14 and Figures 1518 respectively.

Effect of MK content on the Compressive Strength of blended cement mortars at constant RHA content. Figures 11-14 illustrate the effect of MK content on the compressive strength at constant RHA content of 5, 10, 15 and $20 \mathrm{wt} \%$ respectively. It could be observed generally that as the curing days lengthened from 2-60 days, all cement blends and OPC experienced an increase in their mortar compressive strengths despite diminution of the clinker content.

Figure 11 indicated that as the MK content increased from $0-25$ wt $\%$ at 5 wt $\%$ constant RHA, the cement blends produced improved mortar strengths at the various curing days. There was a significant strength gain as the curing days progressed at 28 days and beyond in comparison with control. According to [1], this strength development could be attributed to the high levels of silica and alumina in $\mathrm{MK}$, and an increase in the $\mathrm{C} / \mathrm{S}$ ratio due to $\mathrm{CAH}$ and $\mathrm{CSH}$ produced from interaction with $\mathrm{CH}$, thus providing significant strength gain. Cement blends containing $20 \mathrm{wt} \%$ MK content produced the best mortar compressive strength of $40.5 \mathrm{MPa}$ at curing time beyond 28 days (36\% strength gain compared with OPC control). This improvement was in agreement with $[14,15,17]$ which showed similar trend after 28 days.

It could be observed from Figure 12 that for cement replacement of $5-10 \mathrm{wt} \% \mathrm{MK}$ at $10 \mathrm{wt} \%$ RHA resulted in an enhanced mortar compressive strength compared with control especially after 28 days. Cement blended with $5 \mathrm{wt} \% \mathrm{MK}$ content at $10 \mathrm{wt} \%$ constant RHA produced the best-improved mortar compressive strength beyond 2 days in comparison with OPC. This enhanced strength could be attributed to the high silica content present in the RHA coupled with MK rich in alumina and silica content which produces additional $\mathrm{CSH}$ and $\mathrm{CAH}$ with the residual $\mathrm{CH}$ present in the matrix. Authors [54] indicated a similar trend of improved strength as MK content increased at the replacement of $10-15 \mathrm{wt} \%$. 


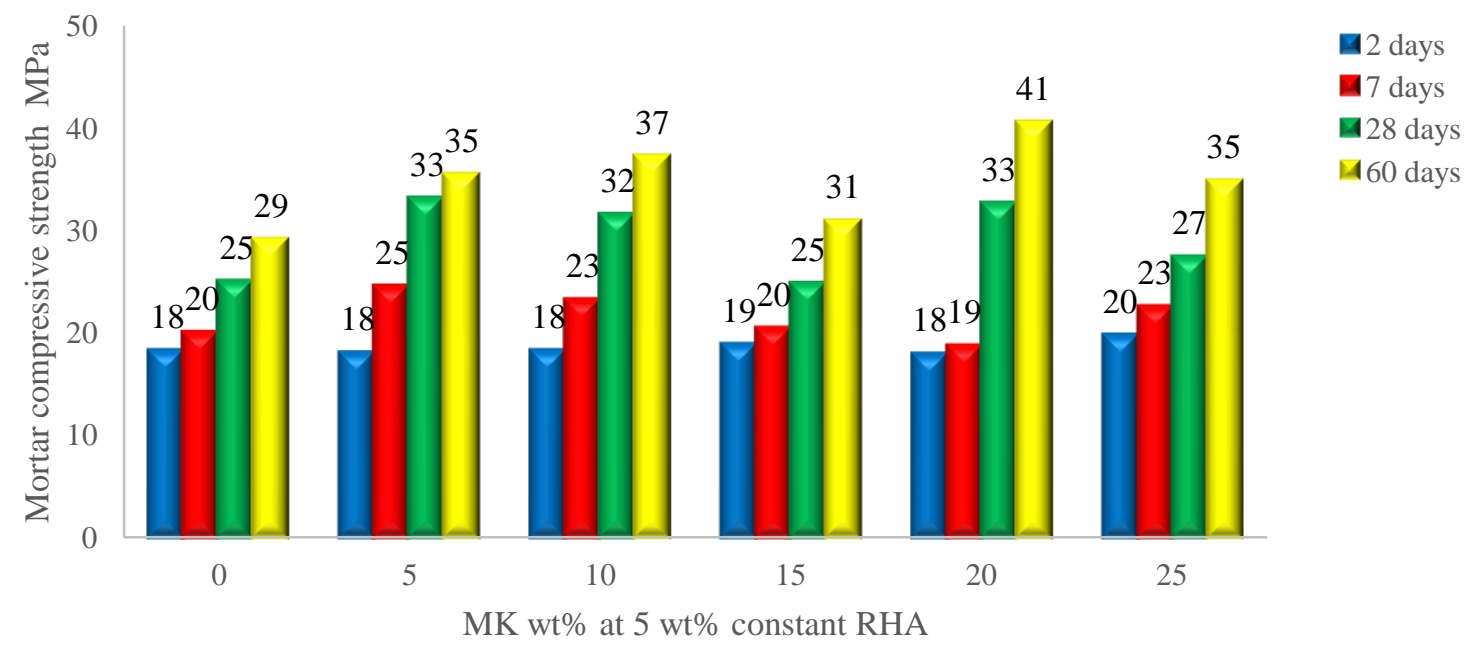

Figure 11 - Effect of MK content on Strength of blends and OPC mortars at $5 \mathrm{wt} \%$ constant RHA

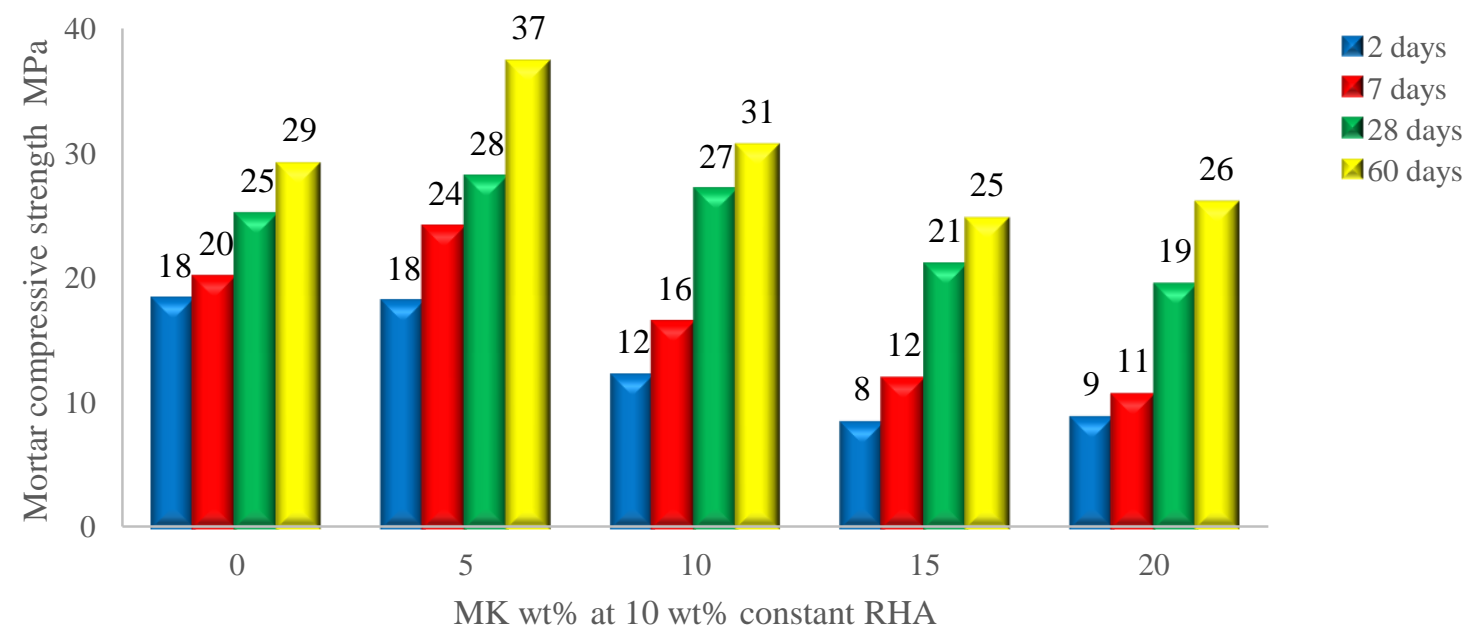

Figure 12 - Effect of MK content on mortar strength of blends at constant 10 wt\% RHA and OPC

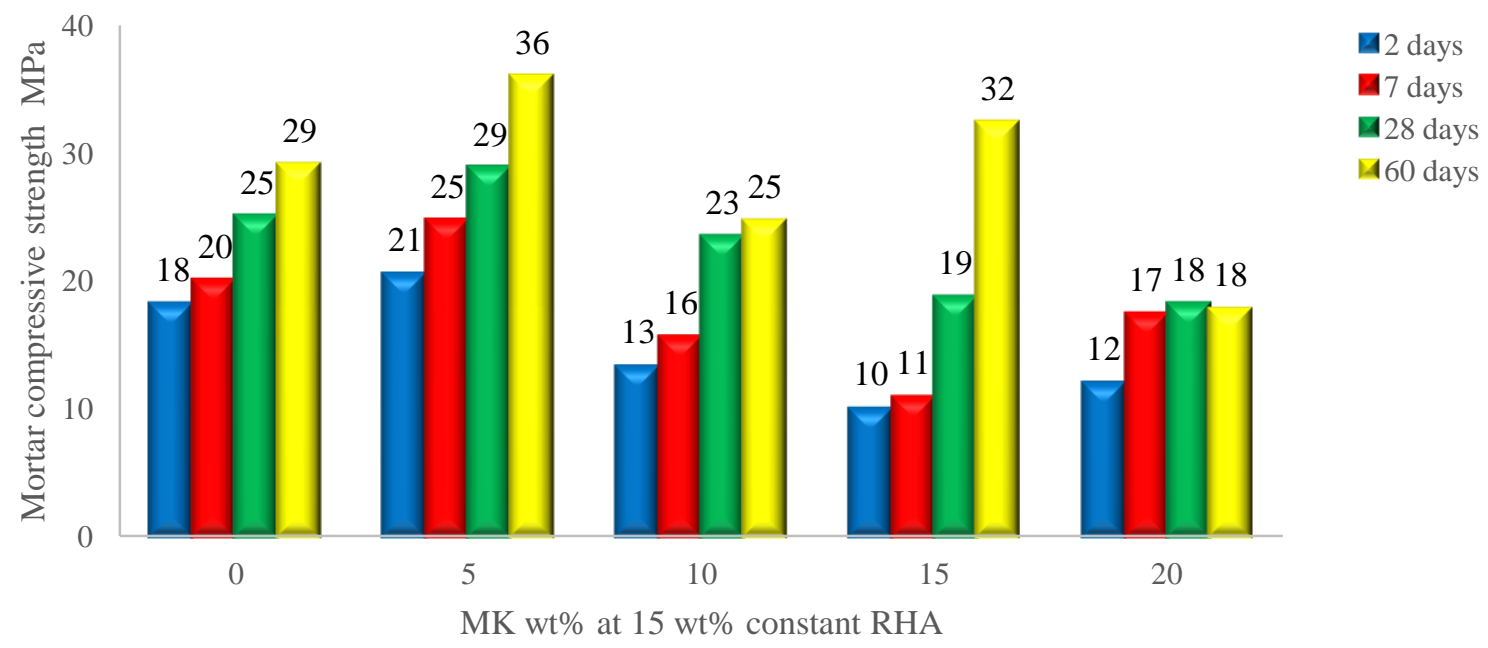

Figure 13 - Effect of MK content on mortar strength of blends at constant $15 \mathrm{wt} \% \mathrm{RHA}$ and OPC 
At $15 \mathrm{wt} \%$ RHA content, an increase in the MK content beyond $5 \mathrm{wt} \%$ produced lower strength in comparison with OPC. As the MK content was gradually increased from $5-20 \mathrm{wt} \%$ at $15 \mathrm{wt} \%$ constant RHA, it could also be observed that after 28 days, most of the blended cement mortar had either attained or exceeded the compressive strength of the control at 60 days expect at 20 wt $\%$ MK. This improved compressive strength of the ternary cement blends could be attributed to the formation of more nucleation sites, resulting in improved reactivity and packing which agrees with [54]. Similar trends of increase in the mortar compressive strength of OPC-MK at constant
RHA increased as the curing time progressed up to 60 days and was observed for $10 \mathrm{wt} \%, 15 \mathrm{wt} \%$ and $20 \mathrm{wt} \%$ constant RHA content as illustrated in Figures 11, 12 and 14 respectively. Cement blended with $5 \mathrm{wt} \% \mathrm{MK}$ produced the highest compressive strength due to $\mathrm{MK}$ acting as a nucleation site resulting in the acceleration of OPC hydration. The decrease in the mortar compressive strength as the cement replacement increased could be due to the diminution of the clinker content which agrees with [63] which also indicated a diminution indicated a diminution in the compressive strength as MK content was increased up to $20 \mathrm{wt} \%$.

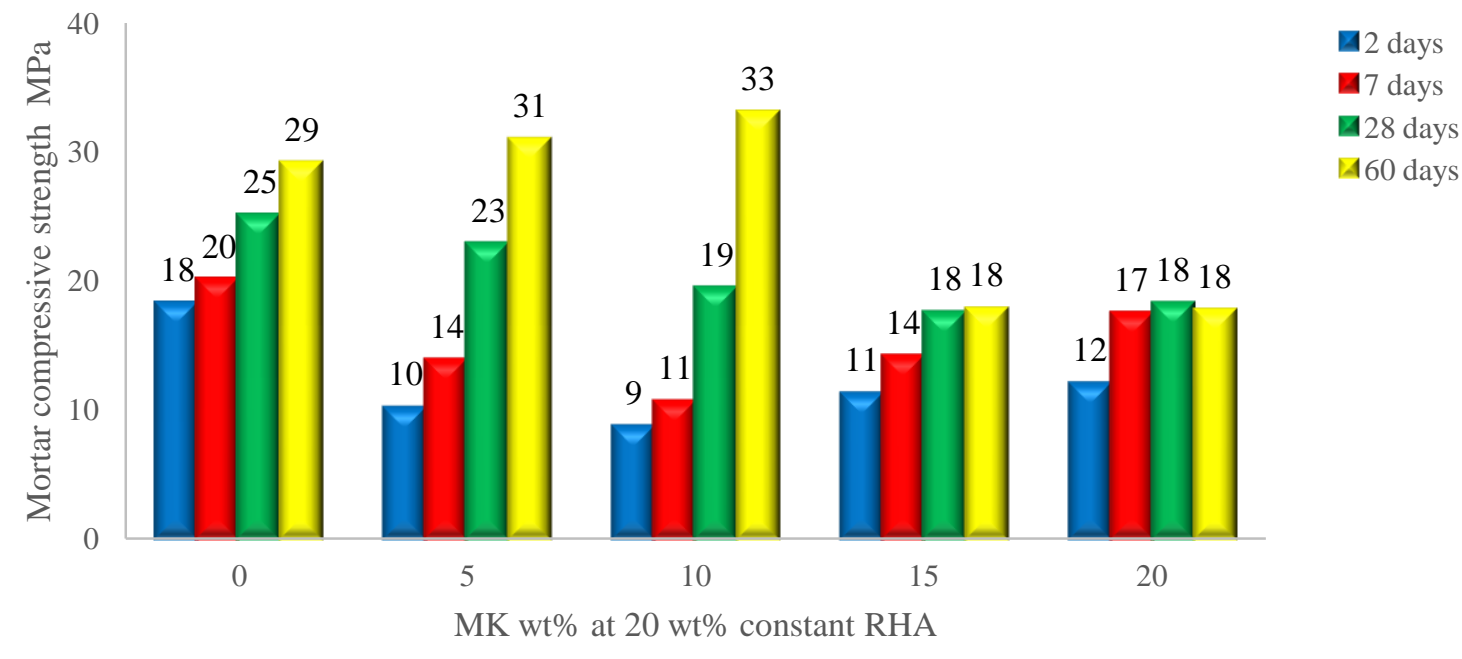

Figure 14 - Effect of MK content on mortar strength of blends at constant 20 wt\% RHA and OPC

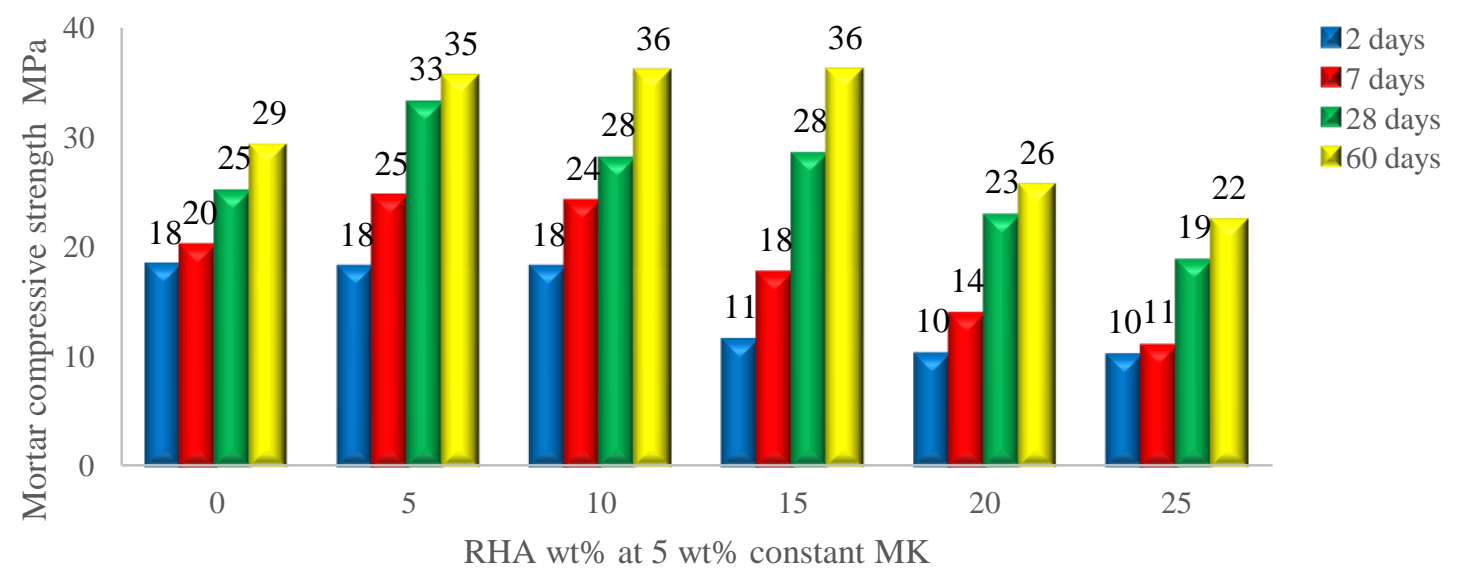

Figure 15 - Effect of RHA content at constant $5 \mathrm{wt} \% \mathrm{MK}$ on compressive strength of blends and OPC mortars

It could be seen from Figure 14 that at the early age up to 28 days, that all blends produced mortar compressive strengths lower than the control which could be related to the dilution of OPC with MK and RHA. Whereas beyond 28 days, the compressive strengths of ternary cement blends with $5 \mathrm{wt} \%$ and $10 \mathrm{wt} \% \mathrm{MK}$ at $20 \mathrm{wt} \%$ constant RHA were better than OPC control. The production of more hydration products like $\mathrm{CSH}, \mathrm{CAH} \&$ $\mathrm{CASH}$ which reduces the available pores resulting in a higher strength according to [64]. 
Effect of RHA at constant MK on the compressive strength of blended cement mortar. Figures 15-18 illustrate the effect of replacing cement with RHA content at 5, 10, 15 and 20 wt\% constant MK content on the mortar compressive strength of ternary cement blends respectively. A significant reduction in the mortar compressive strength of the blended mortar was observed as RHA increased beyond $10 \mathrm{wt} \%$ at $5 \mathrm{wt} \%$ constant MK at 2 days, the mortar compressive strength began to diminish significantly in comparison with control. The reduction in blended cement mortar strengths could be attributed to the high unburnt carbon of the RHA (LOI of $3.36 \mathrm{wt} \%$ ), owing to more water demand. The lower compressive strengths were experienced due to higher water requirements and dilution of Portland cement which agrees with [66]. A reduction in the compressive strength of the blended mortar was experienced when the RHA content was increased beyond $15 \mathrm{wt} \%$ after 7 days in comparison with OPC. The increase in compressive strength up to $15 \mathrm{wt} \%$ despite OPC dilution could be attributed to the pozzolanic activity resulting in enhanced strength. These results agree with the works of $[9,65]$ that RHA inclusion up to $15 \mathrm{wt} \%$ resulted in an enhanced mortar compressive strength beyond which resulted in a decrease in compressive strength. Results indicated a maximum compressive strength of $36 \mathrm{MPa}$ for a ternary blend with $15 \mathrm{wt} \%$ RHA at $5 \mathrm{wt} \%$ constant MK content.

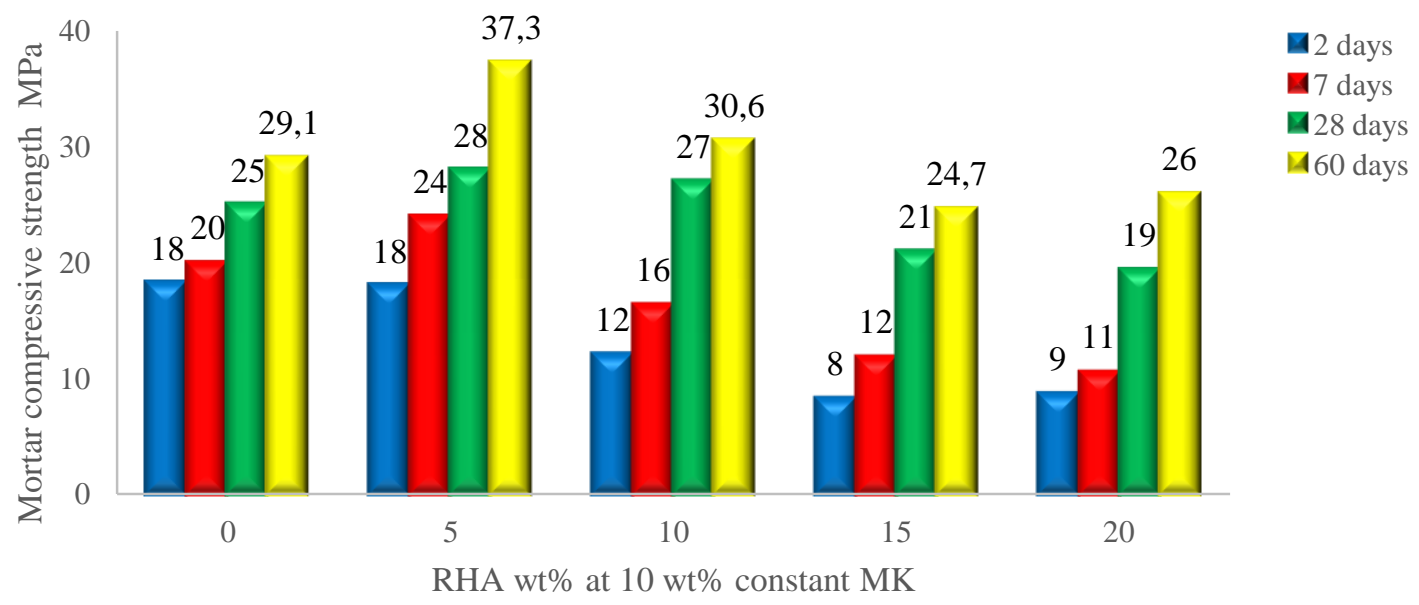

Figure 16 - Effect of RHA content at constant 10 wt\% MK on compressive strength of blends and OPC mortars

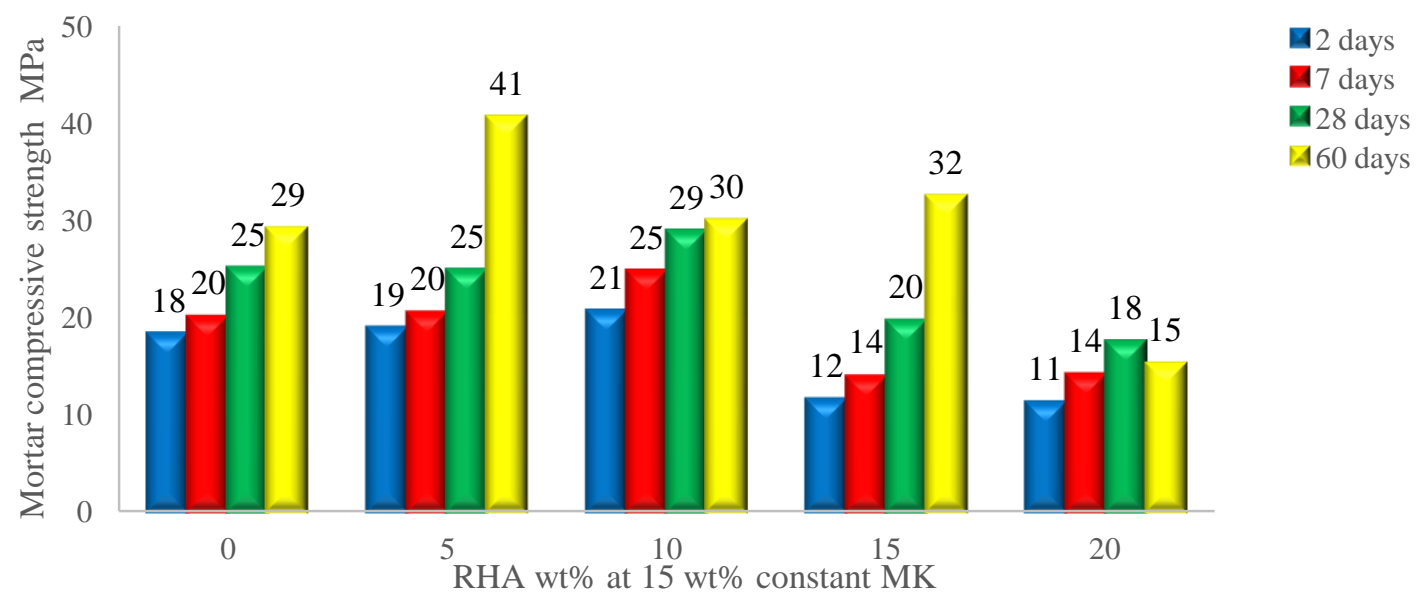

Figure 17 - Effect of RHA content at constant 15 wt\% MK on compressive strength of blends and OPC mortars

From Figure 16, a reduction in the mortar compressive strength beyond $10 \mathrm{wt} \%$ RHA at constant $10 \mathrm{wt} \% \mathrm{MK}$ was observed beyond 7 days whereas beyond $5 \mathrm{wt} \%$ RHA at $10 \mathrm{wt} \%$ constant MK led to a reduction in its strength up to 7 days.
Cement replacement with $5 \mathrm{wt} \%$ RHA at $10 \mathrm{wt} \%$ constant MK produced the best mortar compressive strength of $37.3 \mathrm{MPa}$ at 60 days which could be attributed to the pozzolanic activity leading to 
the formation of more CSH despite clinker diminution [47].

Similarly, the mortar compressive strength of up to $15 \mathrm{wt} \%$ RHA at $15 \mathrm{wt} \%$ constant MK and up to $10 \mathrm{wt} \%$ RHA at $20 \mathrm{wt} \%$ constant MK were higher than OPC control as observed in Figures 17 and 18 respectively. The initial increase in strength may be partially due to the pozzolanic reaction and the presence of reactive silica in RHA according to $[23,66]$. Furthermore, the strength devel- opment of RHA above 15 wt $\%$ cement replacement resulted in a reduction in the compressive strength in comparison to OPC. This is an indication that the optimal cement replacement with RHA should not exceed $20 \mathrm{wt} \%$. This decrease in the mortar compressive strength could either be attributed to the diminution of the clinker (reduction in the $\mathrm{CaO} / \mathrm{SiO}_{2}$ ) content coupled with the presence of unburnt carbon from the high loss of ignition (LOI) content of RHA [28].

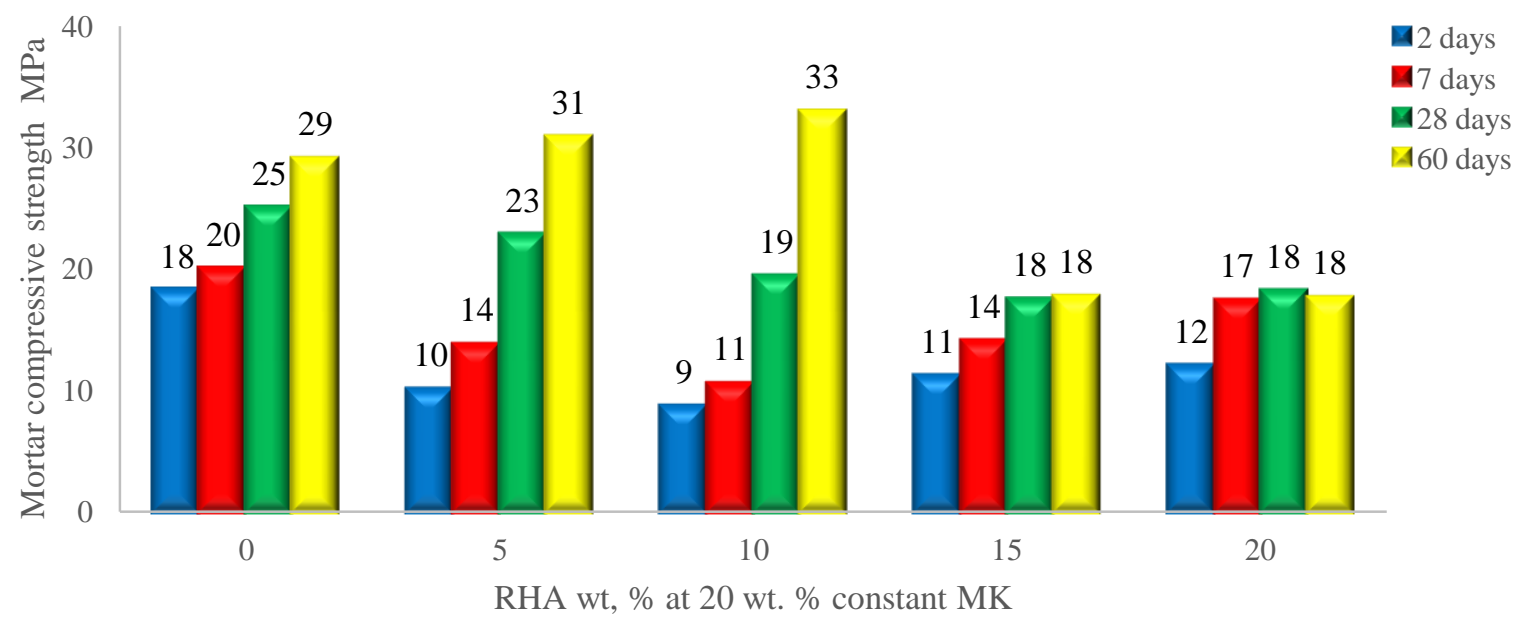

Figure 18 - Effect of RHA content at constant 20 wt\% MK content on Strength of blends and OPC mortars

It was observed that any further increase in the RHA content beyond $10 \mathrm{wt} \%$ at constant $20 \mathrm{wt} \%$ MK resulted in a diminution of the compressive strength at 60 days. In general, MK produced a significant positive effect on the mortar compressive strength compared with RHA since RHA had a high unburnt carbon of 3.36 wt $\%$ which increases the water demand, thereby lowering the compressive strength [28].

\section{CONCLUSION}

The water consistency of ternary cement paste increased with an increase in OPC replacement with MK content up to $25 \mathrm{wt} \%$ at constant RHA content up to $10 \mathrm{wt} \%$. However, beyond $10 \mathrm{wt} \%$, constant RHA content with an increase in MK content results in no significant change (variation) in the water consistency. An increase in RHA content at constant MK content increased the water demands of the ternary blend. This increase could mainly be due to the unburnt carbon present in the RHA matrix.

The initial and final setting times experienced acceleration as the RHA was increased at constant MK content due to the high reactivity and the rapid solubility of the siliceous content in the RHA thus, leading to quicker pozzolanic reactions. Whereas a series of retardations and accelerations of both setting times were experienced as the MK content was increased at constant RHA content.

The volume expansion of the ternary cement paste gradually increases as RHA content increases up to $25 \mathrm{wt} \%$ at constant MK content due to $\mathrm{CaO}$ and $\mathrm{MgO}$ present in RHA. On the other hand, as the MK content increases up to $25 \%$ at constant RHA content, the volume expansion diminished. The increase in volume expansion (volume instability) could be due to $\mathrm{CaO}$ and $\mathrm{MgO}$ present in the RHA. The decrease in volume expansion can be attributed to the diminution of ordinary Portland cement which contains significant content of $\mathrm{CaO} / \mathrm{MgO}$ responsible for unsoundness. The ternary blends produced better and lower volume expansion results in comparison with the control.

The mortar compressive strength of the cement increased as the curing days were lengthened for both OPC and the ternary cement blends. The compressive strengths of the various blended cements showed significant improvement in 
comparison with OPC control which can be attributed to the formation of CSH and CAH from the reaction of the $\mathrm{CH}$ available after cement hydration and the silica and alumina present in $\mathrm{MK}$ and RHA, thus providing significant strength gain. A direct relationship exists between the MK content at constant RHA content and the compressive strength improvement. This can either be attributed to the high silica/ alumina contribution to the matrix or the $\mathrm{C} / \mathrm{S}$ ratio in the cement matrix.

The mortar compressive strengths of MK-RHAOPC blends were generally lower than control mixtures at pre 28 days, whereas, beyond 28 days compressive strengths of MK-RHA-OPC mixture were higher compared to OPC control. Since MK and RHA being highly pozzolanic, they both form additional calcium silicate hydrate and calcium aluminate hydrates by reaction with calcium hydroxide formed upon cement hydration, resulting in increased strength of the blended cement. During the initial stage of cement hydration, a sufficient amount of calcium hydroxide is not available, thus the early strength of blended cement is lower than that of ordinary cement.

Cement replacement of 5 wt\% RHA and up to $25 \mathrm{wt} \%$ MK produced the best strength for the various ternary cement blends. The optimal ternary cement blend for the best mortar compressive strength was between 15-20 wt\% MK and $5 \mathrm{wt} \%$ RHA. Similarly, ternary cement comprising of up to $10 \mathrm{wt} \% \mathrm{MK}$ and up to $10 \mathrm{wt} \% \mathrm{RHA}$ content produced a better strength gain com- pared to OPC control. This favorable behavior of blended cement at different ages was related to the high pozzolanic rate of MK and RHA, transforming the portlandite generated during the OPC hydration into CSH gels.

A decline in the mortar compressive strength of MK-RHA-OPC at 15 wt\% RHA inclusion at constant MK content due to an increase in the water requirement coupled with clinker diminution. On the other hand, the strength gain diminished beyond 28 days was experienced as MK content was gradually increased up to $20 \mathrm{wt} \%$ while RHA was held constant beyond $15 \mathrm{wt} \%$. The mortar compressive strength of cement replacement up to $20 \%$ RHA content at constant MK content experienced an increase followed by a decrease. This variation in the mortar compressive strength could be attributed to RHA's reactivity as well as the unburnt carbon present in the RHA matrix.

\section{ACKNOWLEDGMENT}

The authors acknowledge Dr. Yusuf Makarfi Isa of the Department of Chemical Engineering, Durban University of Technology South Africa for their support to this research work.

\section{CONFLICT OF INTEREST}

The authors declared that they have no conflict of interest.

\section{REFERENCES}

1. Shekarchi, M., Bonakdar, A., Bakhshi, M., Mirdamadi, A., \& Mobasher, B. (2010). Transport properties in metakaolin blended concrete. Construction and Building Materials, 24(11), 2217-2223. doi: 10.1016/j.conbuildmat.2010.04.035

2. Simulation Studies of the Effects of Mineral Admixtures on the Cement Paste-Aggregate Interfacial Zone (SP-105). (1991). ACI Materials Journal, 88(5). doi: 10.14359/2179

3. Sadimantara, G. R., Nuraida, W., Suliartini, N. W. S., \& Muhidin. (2018). Evaluation of some new plant type of upland rice (Oryza sativa L.) lines derived from cross breeding for the growth and yield characteristics. IOP Conference Series: Earth and Environmental Science, 157, 012048. doi: 10.1088/1755-1315/157/1/012048

4. Habeeb, G. A., \& Mahmud, H. B. (2010). Study on properties of rice husk ash and its use as cement replacement material. Materials Research, 13(2), 185-190. doi: 10.1590/s151614392010000200011

5. Kartini, M. (2009). Mechanical, Time-Dependent and Durability Properties of Grade 30 Rice Husk Ash Concrete (Doctoral thesis); University of Malaya.

6. Gambhir, M. L. (2006). Concrete Technology (3rd ed.). New Delhi: Tata McGraw-Hill. 
7. Hwang, C. L., \& Chandra, S. (1996). The use of rice husk ash in concrete. Waste Materials Used in Concrete Manufacturing, 184-234. doi: 10.1016/b978-081551393-3.50007-7

8. Mehta, P. (1992). Rice Husk Ash: A unique supplementary cement material. In V. Malhotra (Ed.), Advance in Concrete Technology, Ottawa, Canada (pp. 407-431).

9. Mahmud, H., Koay, Y., Hamid, N., \& Zain, M. (2002). Use of Rice Husk Ash to produce High Strength / High Performance G80 Concrete. In 6th International Symposium on Utilization of High Strength/ High Performance Concrete (pp. 1161-1173).

10. Rodríguez de Sensale, G. (2006). Strength development of concrete with rice-husk ash. Cement and Concrete Composites, 28(2), 158-160. doi: 10.1016/j.cemconcomp.2005.09.005

11. Abdullahi, M. (2006). The use of rice husk ash in low-cost sandcrete block production. Leonardo Electronic Journal of Practices and Technologies, 8, 58-70.

12. Farah, A., Ramadhansyah, P., Badorul, H., \& Megat, A. (2011). Effect of Rice Husk Ash to the Performance of Concrete block. International Journal of Applied Science and Technology, 1(3), 5361.

13. Clovis, N., Vanderley, M., . Cleber, M., Holmer, S., \& Mario, S. (2004). Effect of metakaolin on the performance of pva and cellulose fibers reinforced cement. Retrieved from https://www.researchgate.net/publication/239553102_EFFECT_OF_METAKAOLIN_ON_THE_P ERFORMANCE_OF_PVA_AND_CELLULOSE_FIBERS_REINFORCED_CEMENT

14. Sabir, B., Wild, S., \& Khatib, J. (1996). On the workability and strength development of metakaolin concrete. In R. Dhir, \& Th. Dyer (Eds.), Concrete for environmental enhancement and protection (pp. 651-656). London: E\&FN Spon.

15. Justice, J. M., \& Kurtis, K. E. (2007). Influence of Metakaolin Surface Area on Properties of CementBased Materials. Journal of Materials in Civil Engineering, 19(9), 762-771. doi: 10.1061/(asce)0899-1561(2007)19:9(762)

16. Zhang, M. H., \& Malhotra, V. M. (1995). Characteristics of a thermally activated alumino-silicate pozzolanic material and its use in concrete. Cement and Concrete Research, 25(8), 1713-1725. doi: 10.1016/0008-8846(95)00167-0

17. Wild, S., Khatib, J. M., \& Jones, A. (1996). Relative strength, pozzolanic activity and cement hydration in superplasticised metakaolin concrete. Cement and Concrete Research, 26(10), 1537-1544. doi: 10.1016/0008-8846(96)00148-2

18. Caldarone, M., Gruber, K., \& Burg, R. (1994). High Reactivity Metakaolin (HRM): A New Generation Mineral Admixture for High Performance Concrete. Concrete International, 16(11), 37-41.

19. Kannan, V., \& Ganesan, K. (2012). Strength and water absorption properties of ternary blended cement mortar using rice husk ash and metakaolin. Scholarly Journal of Engineering Research, 1(4), 51-59.

20. Sandhu, R. K., \& Siddique, R. (2017). Influence of rice husk ash (RHA) on the properties of selfcompacting concrete: A review. Construction and Building Materials, 153, 751-764. doi: 10.1016/j.conbuildmat.2017.07.165

21. Dabai, M., Muhammad, C., Bagudo, B., \& Musa, A. (2010). Studies on the Effect of Rice Husk Ash as Cement Admixture. Nigerian Journal of Basic and Applied Sciences, 17(2). doi: 10.4314/njbas.v17i2.49917

22. Barkakati, P., Bordoloi, D., \& Borthakur, P. C. (1994). Paddy husk as raw material and fuel for making portland cement. Cement and Concrete Research, 24(4), 613-620. doi: 10.1016/00088846(94)90185-6

23. Ganesan, K., Rajagopal, K., \& Thangavel, K. (2008). Rice husk ash blended cement: Assessment of optimal level of replacement for strength and permeability properties of concrete. Construction and Building Materials, 22(8), 1675-1683. doi: 10.1016/j.conbuildmat.2007.06.011 
24. Abu Bakar, B. H., Ramadhansyah, P. J., \& Megat Azmi, M. J. (2011). Effect of rice husk ash fineness on the chemical and physical properties of concrete. Magazine of Concrete Research, 63(5), 313320. doi: $10.1680 /$ macr.10.00019

25. Brown, D. (2012, September). Unprocessed Rice Husk Ash as a Partial Replacement of Cement for Low-Cost Concrete (Master's thesis). Retrieved from https://core.ac.uk/download/pdf/10129738.pdf

26. The relationship between the strength and non-destructive parameters of rice husk ash concrete. (1997). NDT \& E International, 30(4), 261. doi: 10.1016/s0963-8695(97)88972-4

27. Kaya, A. (2010, September). A study on blended bottom ash cements (Master's thesis). Retrieved from http://etd.lib.metu.edu.tr/upload/12612504/index.pdf

28. Olubajo, O., \& Osha, O. (2013). Influence of bottom ash and limestone powder on the properties of ternary cement and mortar. International Journal of Engineering Research and Technology, 2(7), 1201-1212.

29. Dashan, I., \& Kamang, E. (1999). Some characteristics of RHA/OPC Concretes: A Preliminary Assessment. Nigerian Journal of Construction Technology and Management, 2(1), 22-28.

30. Rajput, J., Yadav, R., \& Chandak, R. (2013). The Effect of Rice Husk Ash used as Supplementary Cementing Material on Strength of Mortar. International Journal of Engineering Research and Applications, 3(3), 133-136.

31. Godwin, A., Maurice, E., Akobo, I., \& Ukpata, J. (2013). Structural Properties of Rice Husk Ash Concrete. International Journal of Engineering and Applied Sciences, 3(3), 57-62.

32. Bhushan, Er., Gochhe, S., Bastola, B. (2017). Partial Replacement of Cement by Rice husk ash. International Research Journal of Engineering and Technology, 4(10), 251-256.

33. Kamau, J., Ahmed, A., Hyndman, F., Hirst, P., \& Kangwa, J. (2017). Influence of Rice Husk Ash Density on the Workability and Strength of Structural Concrete. European Journal of Engineering Research and Science, 2(3), 36. doi: 10.24018/ejers.2017.2.3.292

34. Shetty, M. (2007). Concrete technology: theory and practice. New Delhi: S. Chand.

35. Page, C., \& Page, M. (2007). Durability of concrete and cement composites. Boca Raton: CRC Press.

36. Bapat, J. (2013). Mineral admixtures in cement and concrete. Boca Raton: CRC Press.

37. Minh, Le T., \& Tram, N. (2017). Utilization of Rice Husk Ash as partial replacement with Cement for production of Concrete Brick. Retrieved from https://www.matecconferences.org/articles/matecconf/pdf/2017/11/matecconf_etic2017_01121.pdf

38. Kulkarni, M., Mirgal, P., Bodhale, P., Tande, S. (2014). Effect of Rice Husk Ash on Properties of Concrete. Retrieved from https://www.researchgate.net/publication/270600080_Effect_of_Rice_Husk_Ash_on_Properties _of_Concrete

39. Kumar, A., Tomar, A., Gupta, Sh., \& Kumar, A. (2016). Replacement of Cement in Concrete with Rice Husk Ash. SSRG International Journal of Civil Engineering, 3(7), 127-134.

40. Varshney, H. (2016). Utilization of Rice Husk Ash in concrete as cement replacement. IOSR Journal of Mechanical and Civil Engineering, 01(01), 28-33. doi: 10.9790/1684-15010010128-33

41. Rashid, M. (2016). Strength Behavior of Cement Mortar Assimilating Rice Husk Ash. International Journal of Advances in Agricultural and Environmental Engineering, 3(2). doi: 10.15242/ijaaee.a0416059

42. Rukzon, S., Chindaprasirt, P., \& Mahachai, R. (2009). Effect of grinding on chemical and physical properties of rice husk ash. International Journal of Minerals, Metallurgy and Materials, 16(2), 242-247. doi: 10.1016/s1674-4799(09)60041-8 
43. Matahula, W., \& Olubajo, O. (2018). Effects of Limestone and Coal Bottom Ash on Setting Time of Blended Portland Cement (Ternary Cement). Journal of Material Science \& Engineering, 07(05). doi: 10.4172/2169-0022.1000484

44. Ologunagba, I., Daramola, A., \& Aliu, A. (2015). Feasibility of using Rice Husk Ash as Partial Replacement for Concrete. International Journal of Engineering Trends and Technology, 30(5), 267-269. doi: 10.14445/22315381/ijett-v30p250

45. Singh, P., Singh, T., \& Singh, G. (2016). To Study Strength Characteristics of Concrete with Rice Husk Ash. Indian Journal of Science and Technology, 9(47). doi: 10.17485/ijst/2015/v8i1/105272

46. Aleem, M., Rahim, I., Awan, U., Afzal, U., \& Haseeb, U. (2015). Incorporation of Rice Husk Ash as Cement Replacement. Journal of Engineering, 5(7), 25-30.

47. Olubajo, O., Osha, O., El-Natafty, U., \& Adamu, H. (2017). A study on Coal bottom ash and limestone effects on the hydration and physico-mechanical properties of ternary cement blends. Abubakar Tafawa Balewa University.

48. Olubajo, O., Waziri, S., Aderemi, B. (2014). Kinetic of the decomposition of alum sourced from Kankara Kaolin. International Journal of Engineering Research and Technology, 3(2), 1629-1635.

49. Bureau of Indian Standards. (1988). Methods of physical tests for hydraulic cement. Part 4: Determination of consistency of standard cement paste (IS 4031: 1988). New Delhi: Bureau of Indian Standards.

50. Bureau of Indian Standards. (1988). Methods of physical tests for hydraulic cement. Part 3 Determination of soundness of cement paste (IS 4031: 1988). New Delhi: Bureau of Indian Standards.

51. Raheem, A. A., \& Kareem, M. A. (2017). Chemical Composition and Physical Characteristics of Rice Husk Ash Blended Cement. International Journal of Engineering Research in Africa, 32, 25-35. doi: 10.4028/www.scientific.net/jera.32.25

52. Rukzon, S., \& Chindaprasirt, P. (2010). Strength and carbonation model of rice husk ash cement mortar with different fineness. Journal of Materials in Civil Engineering, 22(3), 253-259.

53. Zerbino, R., Giaccio, G., \& Isaia, G. C. (2011). Concrete incorporating rice-husk ash without processing. Construction and Building Materials, 25(1), 371-378. doi:

10.1016/j.conbuildmat.2010.06.016

54. El-Diadamony, H., Amer, A. A., Sokkary, T. M., \& El-Hoseny, S. (2018). Hydration and characteristics of metakaolin pozzolanic cement pastes. HBRC Journal, 14(2), 150-158. doi:

10.1016/j.hbrcj.2015.05.005

55. Fernandez, R., Martirena, F., \& Scrivener, K. L. (2011). The origin of the pozzolanic activity of calcined clay minerals: A comparison between kaolinite, illite and montmorillonite. Cement and Concrete Research, 41(1), 113-122. doi: 10.1016/j.cemconres.2010.09.013

56. Brooks, J. J., Megat Johari, M. A., \& Mazloom, M. (2000). Effect of admixtures on the setting times of high-strength concrete. Cement and Concrete Composites, 22(4), 293-301. doi: 10.1016/s09589465(00)00025-1

57. Wang, B. M., Ma, H. N., Li, M., \& Han, Y. (2013). Effect of Metakaolin on the Physical Properties and Setting Time of High Performance Concrete. Key Engineering Materials, 539, 195-199. doi: 10.4028/www.scientific.net/kem.539.195

58. Mahmud, H., Chia, B., Hamid, N. (1997, June). Rice husk ash - an alternative material in producing high strength concrete. In Proceedings of International Conference on Engineering Materials, Ottawa, Canada (pp. 275-284).

59. Sathawane, S. H., Vairagade, V. S., \& Kene, K. S. (2013). Combine Effect of Rice Husk Ash and Fly Ash on Concrete by 30\% Cement Replacement. Procedia Engineering, 51, 35-44. doi:

10.1016/j.proeng.2013.01.009 
60. Marthong, C. (2012). Effect of Rice Husk Ash (RHA) as Partial Replacement of Cement on Concrete Properties. International Journal of Engineering Research \& Technology, 1(6), 1-9.

61. Badogiannis, E., Kakali, G., Dimopoulou, G., Chaniotakis, E., \& Tsivilis, S. (2005). Metakaolin as a main cement constituent. Exploitation of poor Greek kaolins. Cement and Concrete Composites, 27(2), 197-203. doi: 10.1016/j.cemconcomp.2004.02.007

62. Chatterji, S. (1995). Mechanism of expansion of concrete due to the presence of dead-burnt CaO and Mg0. Cement and Concrete Research, 25(1), 51-56. doi: 10.1016/0008-8846(94)00111-b

63. Didamony, H., Abo-EL-Enein, S., Ali, A., \& El-Sokkary, T. (1999). Effect of silica fume on the slag cement containing wet cement dust. Indian Journal of Engineering \& Material Science, 6, 274278.

64. Eckart, V., Ludwig, H.-M., \& Stark, J. (1995). Hydration of the four main Portland cement clinker phases. Zem-Kalk-Gip International, 28(8), 443-452.

65. Al-Abdaly, N. (2007). Drying shrinkage cracking of high strength concrete (Master's thesis); Babylon University.

66. Hwang, C. L., \& Chandra, S. (1996). The use of rice husk ash in concrete. Waste Materials Used in Concrete Manufacturing, 184-234. doi: 10.1016/b978-081551393-3.50007-7

67. Olubajo, O., Osha, O., El- Nafaty, U., \& Adamu, H. (2014). Effect of water-cement ratio on the mechanical properties of blended cement containing bottom ash and limestone. Civil and Environmental Research, 6(12), 1-9. 